\title{
Is the Implicit Association Test a Valid and Valuable Measure of Implicit Consumer Social Cognition?
}

\author{
Frédéric F. Brunel \\ Boston University \\ Brian C. Tietje \\ Cal Poly State University \\ Anthony G. Greenwald \\ University of Washington
}

\begin{abstract}
This article discusses the need for more satisfactory implicit measures in consumer psychology and assesses the theoretical foundations, validity, and value of the Implicit Association Test (IAT) as a measure of implicit consumer social cognition. Study 1 demonstrates the IAT's sensitivity to explicit individual differences in brand attitudes, ownership, and usage frequency, and shows their correlations with IAT-based measures of implicit brand attitudes and brand relationship strength. In Study 2, the contrast between explicit and implicit measures of attitude toward the ad for sportswear advertisements portraying African American (Black) and European American (White) athlete-spokespersons revealed different patterns of responses to explicit and implicit measures in Black and White respondents. These were explained in terms of self-presentation biases and system justification theory. Overall, the results demonstrate that the IAT enhances our understanding of consumer responses, particularly when consumers are either unable or unwilling to identify the sources of influence on their behaviors or opinions.
\end{abstract}

Understanding of consumers' mental states has been a chief concern in consumer research. It is therefore not surprising that psychology has had a profound paradigmatic impact on the field. Like psychologists, consumer researchers have relied heavily on "self-reports of attitudes, stereotypes and other beliefs, preferences, values, goals and motives" (Kihlstrom, 2004, p. 195). Although these procedures have been efficient, convenient, and economical measures and have brought great advances, the advances have been contingent on key assumptions. It has been assumed generally that "people were aware of their attitudes, beliefs, and values that guided their behavior, and that they would be willing to reveal them if asked appropriately" (Kihlstrom, 2004, p. 195). Of course, these assumptions might not always be valid, as people are sometimes unable or unwilling to reveal their opinions (Greenwald \& Banaji, 1995).
Often, consumers are aware of their own attitudes or opinions but are reluctant to share them with unfamiliar researchers. This is usually true of questions that are highly charged, where responses might be embarrassing or where people feel compelled to produce a socially acceptable answer (Kihlstrom, 2004). Then, consumers might resort to impression management and report distorted answers. For example, "dark side behavior" research is often susceptible to socially desirable responding (Mick, 1996). Self-report measures of constructs such as vanity (Netemeyer, Burton, \& Lichtenstein, 1995) and stigmatized behaviors (e.g., compulsive shopping, Mowen \& Spears, 1999; or smoking, Rozin \& Singh, 1999) may also be prone to response management. Procedures that could measure these constructs at the implicit level would provide quantifiable insights into the underlying automatic associations that consumers make. In addition, a substantial portion of consumption is shaped by cognitive processes that are outside conscious awareness (e.g., Bargh, 2002; Zaltman, 2000) and have influences that consumers do not realize (Greenwald \& Banaji, 1995). Re- 
cently, psychologists have shown renewed interest in this issue and have "reclaimed" the importance of the unconscious (Greenwald, 1992; Weinberger, 2000). Although implicit social cognition is still in its infancy, a surge of research has led to measurement and theoretical advances (Fazio \& Olson, 2003). We believe that consumer psychology should build on this movement and that more research should investigate implicit consumer social cognition: ${ }^{1}$ that is, the automatic consumer affective processes and cognitions that exist outside of conscious awareness or control.

However, measurement issues have often constrained our understanding of implicit effects. Although researchers agree that "valid measurement is the sine qua non of science" (Peter, 1979, p. 6), a lack of satisfactory implicit measurement tools has led consumer psychologists to depend a lot on explicit measures. For example, research on incidental ad exposure (Janiszewski, 1993; Shapiro, 1999) assumes that preferences are "formed independently of conscious processing" (Janiszewski, 1988, p. 200). At the same time, however, this research relies on self-report measures of attitude toward the ad (Aad), recognition, and familiarity. In sum, whether it be to circumvent the willingness or awareness issue, the availability of valid implicit measures has become a theoretical imperative (Greenwald \& Banaji, 1995).

In this article, we (a) review the strengths and limitations of past explicit and implicit measures; (b) assess the properties and relevance of the Implicit Association Test (IAT; Greenwald, McGhee, \& Schwartz, 1998) as a measure of implicit consumer social cognition; (c) offer empirical tests of the IAT's validity and sensitivity in a consumer behavior setting; and (d) investigate whether the IAT is able to detect consumer behavior effects that explicit measures cannot. First, we discuss the merits and shortcomings of existing measures. We next describe the IAT from procedural and conceptual perspectives, examine its validity and limitations and explain how it can be used in consumer research. Then, in Study 1, we test the validity and convergence of IAT-based measures of implicit brand attitudes and consumer-brand relationship strength, contrasting them with explicit measures of brand attitude, brand ownership, and brand usage in a context where consumers would be willing and able to share their evaluations (i.e., computer brands). In Study 2, we report a divergence between IAT-based and explicit measures of attitudes toward sportswear advertise-

\footnotetext{
${ }^{1}$ Although published research suggests that there is not complete agreement on terminology, we use implicit versus explicit as a key delineation for both measures and processes. This is consistent with the use of these terms in social psychology, cognitive psychology, and consumer psychology. Other labels have also been used: for example, unaware versus aware, unobtrusive versus obtrusive, unconscious versus conscious, automatic versus controlled, and indirect versus direct. Although related, these terms have slightly different theoretical underpinnings. We believe that the labels implicit versus explicit are most appropriate for this research, and are consistent with the terminology used in recent review articles (Fazio \& Olson 2003; Kihlstrom, 2004)
}

ments that portray African American and White athletes. In this experiment, unlike the first, some respondents were likely to exert control over their answers to conform to social desirability. In a subsequent follow-up study, we eliminate alternative explanations for these findings and confirm that IAT effects are driven by evaluations of the category being tested rather than evaluations of specific category exemplars. Finally, we discuss theoretical and measurement implications of the results.

\section{EXPLICIT AND IMPLICIT MEASURES IN CONSUMER RESEARCH}

\section{Explicit Measures}

Most research on consumer social cognition has used explicit measures of attitudes. There is ample evidence that these measures satisfy important psychometric criteria such as usefulness and efficiency (Mischel, 1968). Nevertheless, they have limitations. The measures (e.g., Likert-type or semantic differential scales) typically reference a target object in the participant's personal history (Jacoby, Lindsay, \& Toth, 1992). Thus, they assume that the participant (a) has already formed an opinion or is able to construct one on the spot (see Schwarz \& Bohner, 2001, for a discussion of the constructionist perspective); (b) is aware of (i.e., has access to) his or her attitude; and (c) is willing to share it accurately with the researcher. This article does not debate whether attitudes are formed, stored, and retrieved or whether they are constructed online. It would nonetheless be tenuous to assume that all conditions can be met in all situations (Jacoby et al., 1992). For our purpose, the last two conditions are critical.

Awareness and willingness issues can be apparent in several ways. First, individuals who have never heard of a topic are unlikely to have formed a prior attitude. To avoid appearing ignorant, however, they might still answer the question (Hawkins \& Coney, 1981). In other cases, previously formed attitudes may not be easily accessible to the individual (Fazio, 1986; Fazio, Sanbonmatsu, Powell, \& Kardes, 1986). Thus, although individuals have a previously formed opinion, they report a newly created one. In addition, even if participants can identify a prior experience, they may be unaware of its influence, hence providing inaccurate reports (Greenwald \& Banaji, 1995). Also, respondents might purposefully distort their answers for social-desirability or image-management reasons. Distortions are especially likely when an accurate response is seen as either violating social norms such as politeness or prejudice (Demo, 1985; Dovidio \& Fazio, 1992), jeopardizing one's self-image (Dovidio \& Fazio; Gaertner \& Dovidio, 1986; Sirgy, 1982), or going against the stereotypical answer (Haire, 1950). In short, no explicit measure can truly avoid the influence of respondents' control. 


\section{Implicit Measures}

Because explicit measures are subject to conscious and unconscious representations, implicit measures should uncover different associations (Banaji \& Hardin, 1996; Devine, 1989; Greenwald et al., 1998). In other words, implicit measures are not "explicit measures without bias' and they do not always assess constructs identical to those assessed by explicit measures. Although related, the two types of measures stem from different information processing streams and appear linked to activations in different regions of the brain (Cunningham, Johnson, Gatenby, Gore, \& Banaji, 2003). However, several factors, such as the type of object being assessed, self-presentation, or attitude elaboration, can influence the correlation between them (Nosek \& Banaji, 2002).

The exact nature of implicit attitudes and measures is subject to debate (e.g., see Banaji, 2001, for a fervent essay on this issue; or Kihlstrom, 2004, for an alternative perspective). Part of the controversy stems from conceptual issues. Some measures can be characterized as unobtrusive but not as implicit per se. In this restricted sense, they are used when people are aware of their attitudes, beliefs, or values but are unwilling to divulge them. However, these unobtrusive measures have no merit if the investigation is concerned with the measurement of implicit constructs (Kihlstrom, 2004) and the consumer has no awareness of the construct of interest. Whereas implicit measures often can be used instead of unobtrusive measures, the opposite is not true. Implicit measures make no reference to objects in a participant's personal history (Greenwald \& Banaji, 1995). Instead, they focus a participant's attention on performing some task that can indirectly reveal the underlying construct such that inaccessible and closely held attitudes can be measured. For example, Greenwald and Banaji (1995) defined implicit attitudes as "introspectively unidentified (or inaccurately identified) traces of past experience that mediate favorable or unfavorable feelings, thoughts, or action toward social objects" (p. 8). As already mentioned, we should not look at implicit measures as a "bona fide pipeline" (Fazio, Jackson, Dunton, \& Williams, 1995) that allows the measurement of "true" attitudes. Indeed, "bona fide pipeline" only indicates that the "automatic activation occurs farther upstream than the overt response to an explicit measure" (Fazio \& Olson, 2003; p. $304)$, not that one is true and the other is not.

Unstructured implicit measures. Generally, implicit measures can be categorized as either disguised-unstructured or disguised-structured (Campbell, 1950). They are disguised because participants are aware they are participating in a study but are typically unaware of what is truly being assessed. Response alternatives can range from open and unstructured to a few structured alternatives (Lemon, 1973). Projective measures (e.g., Rorschach Inkblot Test, the Thematic Apperception Test) are unstructured measures that ask participants to react to a deliberately ambiguous stimulus. In the process of completing the task, participants project parts of themselves (e.g., attitudes, prejudices, fears, etc.) that can then be interpreted (e.g., Haire, 1950).

Sentence or word completion and word association tests are also used frequently. They are more structured than projective techniques because the stimulus is less ambiguous and the response options are more focused. Many projective techniques have their roots in Freudian psychology, and although they continue to be popular in psychoanalytic circles and in some marketing settings (especially in the case of sentence completion, word association, or collages), all have serious shortcomings. Even as projective techniques were intended to help measurement in situations where respondents do not know something or are unable to communicate it (Rapaport, Gill, \& Schafer, 1968), these measures often lack convergent validity and are poor psychometric instruments (Lilienfeld, Wood, \& Garb, 2001). Further, specific conclusions (other than rich qualitative descriptions) can often be flawed because of difficulties in coding and interpretation of qualitative data (Churchill, 1995). Thus, their use should be discouraged in causal, normative, or prescriptive settings where specific and accurate measurements are needed.

Structured implicit measures. By limiting response options, structured measures gain objectivity and avoid most interpretation problems. With these measures, a participant's attention is focused on the completion of a task (e.g., grouping pictures or words) with defined or undefined success criteria. Although these and explicit measures have convergent validity, it is difficult to conceal the research goals in these tasks (Lemon, 1973), and so image management remains an issue. An information test is another type of structured implicit measure. It determines a participant's knowledge of a topic and has clearly defined success criteria. Because a participant's attitude toward a topic should guide the selection and retention of knowledge, this test provides an implicit measure of that attitude (Campbell, 1950; Churchill, 1995). Information tests are robust to social desirability if the purpose can be disguised (Lemon, 1973) but may be confounded by need for cognition (Haugvedt, Petty, \& Cacioppo, 1992). Other measures with defined success criteria and robustness to social desirability ask participants to estimate a group's opinion or identify the social norms of an event. However, they do not provide any information about the automaticity of attitude activation (Dovidio \& Fazio, 1992). This is important because the stronger the associative network around an attitude object, the more automatically the attitude will be activated, even if the attitude is weak (Bargh, 1989) or not consciously held (Fazio, 1986; Fazio et al., 1986).

Sequential priming (Bargh, Chaiken, Govender, \& Pratto, 1992; Fazio et al., 1986) is a structured implicit measure that does not suffer some of the previously mentioned limitations. In these tasks, participants classify (target) words into categories whereas the effect of the preceding (prime) stimulus on classification speed is observed. A typical priming effect 
is that the participant's speed of classifying the target is greater when the prime is associated with the target than when it is not. Priming is flexible and can use verbal or nonverbal (e.g., pictures, shapes, faces) stimuli (Tulving \& Schacter, 1990). Variations of classic priming research have been used to consider attitude activation. Response latencies in the course of classifying target words as positive or negative in evaluation are treated as measures of automatic attitude activation with the assumption that the "effect varies as a function of associative strength" (Fazio, 2001, p. 123).

Effects of priming have been identified using both subliminal and conscious level exposures (e.g., Fazio et al., 1986; Greenwald, Klinger, \& Liu, 1989). As Bargh (1994) noted, "what matters more than whether one is aware of a stimulus event is whether one is aware of the potential influence of that event on subsequent experience and judgments" (p. 15). Applications have included the following: the effect of television programming on perceptions of social reality (Shrum, Wyer, \& O'Guinn, 1998); contextual effects on print (Yi, 1993) and television advertising (Schmitt, 1994); and racial attitudes and prejudice (Devine, 1989; Kawakami, Dion, \& Dovidio, 1998).

Priming research has also established limitations for the measure. In particular, effects can be detected even with weak primes, and the recency of prior access to the attitude toward the prime might affect priming results by increasing the activation level of the association (Bargh et al., 1992). Also, priming measures often have relatively low internal consistency and test-retest reliability (both often below .3). In this case, priming measures are relatively insensitive to individual differences (Bargh et al., 1992; Chaiken \& Bargh, 1993). Finally, priming might have more value as a dependent measure (where larger between groups experimental effects with minimal between-subject variance are desired) than as an independent variable where more between-subjects variance is needed (Kihlstrom, 2004).

Summary. Researchers in consumer psychology often need implicit measures of attitude when consumers are either unaware or unwilling to reveal their opinions. However, empirical advances may have been limited by psychometric shortcomings of the measures that have been employed. Consumer research would benefit from measures that display greater convergent validity, reliability, sensitivity to individual differences, and resilience to the effects of image management and attitude accessibility. The IAT is examined as a prospective solution to these measurement problems.

\section{THE IMPLICIT ASSOCIATION TEST}

The IAT, which was formally introduced in 1998 (Greenwald et al.), has gained rapid recognition (Kihlstrom, 2004) and has become the most well-known implicit measure in psychology (Fazio \& Olson, 2003). The IAT has been used to measure product attitudes (Maison, Greenwald, \& Bruin, 2001, 2004) and various implicit constructs in social psychology (see Fazio \& Olson 2003; Greenwald et al., 2002; or Kihlstrom, 2004, for reviews). To date, however, consumer psychologists have not thoroughly probed the relevance, validity, and general value of this measure. We first examine the basic mechanics of the IAT and discuss the theoretical foundations of its measurement applications. We then turn our attention to more specific measurement issues including face, content, and external validity and reliability. Finally, we discuss some limitations and pending issues.

\section{Conceptual and Measurement Description}

The IAT is based on the premise that attitudes, stereotypes, self-concepts, and self-esteem can be defined as associations between concepts (Greenwald et al., 2002). This theoretical approach is consistent with the associative network view of memory (Anderson \& Bower, 1973; Collins \& Loftus, 1975) and the description of an attitude as the association between an attitude-object and a valence concept (Fazio, 1995; Fazio, Chen, McDonel, \& Sherman, 1982). Therefore, the IAT was developed to measure the relative strength of automatic association between concepts. For example, the first demonstration of the IAT (Greenwald et al., 1998) compared the relative strength of the association between flowers versus insects (the target concepts) and positive versus negative valence. Persons with a more favorable attitude toward flowers than insects possessed a stronger automatic association of "flower" with "positive" than of "insect" with "positive." Besides its ability to measure relative favorableness, the IAT has been shown to be a broader measure, for instance, in the measurement of the association between one's concept of self and other constructs (e.g., women possess stronger IAT-measured associations between "me" and "feminine" than between "me" and "masculine;" Greenwald \& Farnham, 2000).

\section{Modus Operandi}

Based on computer-mediated response latency measurement protocols, the IAT measure is computed by comparing the relative response times associated with several categorization tasks. Assume for purposes of illustration that you are an enthusiastic New York Yankees fan who has a general distaste for the New York Mets (two contrasted attitude-object concepts), and that our purpose is to gauge the relative strength of the automatic association between yourself and the Yankees versus yourself and the Mets. For this task, we might use two pairs of concepts: "Yankees" versus "Mets," and "self" versus "others." For each of the four concepts, we identify a series of words or pictures to use as exemplars. For example, a photo of a Yankees uniform would be an exemplar of "Yankees," whereas "me" would be an exemplar of "self." In the first category discrimination task, several exemplars of the Yankees and Mets are randomly presented with instructions 
to categorize each stimulus as representing either the category "Yankees" or "Mets" by pressing either a specific left or right key on your computer keyboard. In the second discrimination task, exemplars of "self" and "others" are randomly presented with instructions to categorize them as representing "self" or "others" by pressing the appropriate left or right keys.

After completing several trials of these first two tasks, you are asked to complete a new discrimination task where all four categories are now combined. In this task, you are presented with stimuli representing one of the four concepts ("self," "others," "Yankees," or "Mets"), and instructed to press the left key if the stimulus exemplifies either the "self" or "Yankees," and the right key if the stimulus represents either the "others" or "Mets." Thus, "Yankees" and "self" share one response key, and the "Mets" and "others" share the other key. Finally, after some additional practice trials to familiarize yourself with new key assignments for one of the categorization tasks (in this case, "Mets" vs. "Yankees"), you perform a new combined categorization task in which the categorization of "Mets" or "self" is done with the left key, and the categorization of "Yankees" or "others" is done with the right one. If you are a real Yankees fan and identify with the team, you should find the first combined categorization to be easier than the second one. You should also be faster at classifying "Yankees" and "self" exemplars when both categories share the same response key (and "Mets" and "others" share the second response key) than when the key assignments are reversed. The difference between your average response time in the second combined task and your average response time in the first combined task is the IAT effect. Its magnitude and arithmetic sign can be interpreted as a measure of the relative automatic association between yourself and the Yankees, versus yourself and the Mets.

\section{What Does or Can the IAT Measure?}

As the use of the IAT develops, we must consider the scope of the constructs that the measure can assess in psychology, and in consumer research in particular. According to "A Unified Theory of Implicit Attitudes, Stereotypes, Self Esteem, and Self-Concept" (Greenwald et al., 2002), a person's social knowledge structure can be represented by an associative network of concepts and nodes, with social constructs conceptualized as sets of associations. Concepts can be persons, groups, or attributes (including the positive and negative valence attributes). In a typical knowledge structure, the concept of self is at the center and is connected to other social concepts (Greenwald et al., 2002). The IAT provides valid measures of implicit associations in this type of structure and affords data that explicit measures cannot (Greenwald et al., 2002). Overall, the IAT can provide implicit measures of automatic attitudes, self-concepts, self-esteems, and stereotypes.

It follows that the IAT can be used to measure implicit consumption-related constructs in an associative consumer social knowledge structure. Figure 1 represents a hypothetical structure for a visual artist computer user. The consumer is at the center of the structure; general (persons, groups, or attributes) and positive-negative-valence concepts are included. The nodes depict concepts and the line thickness de-

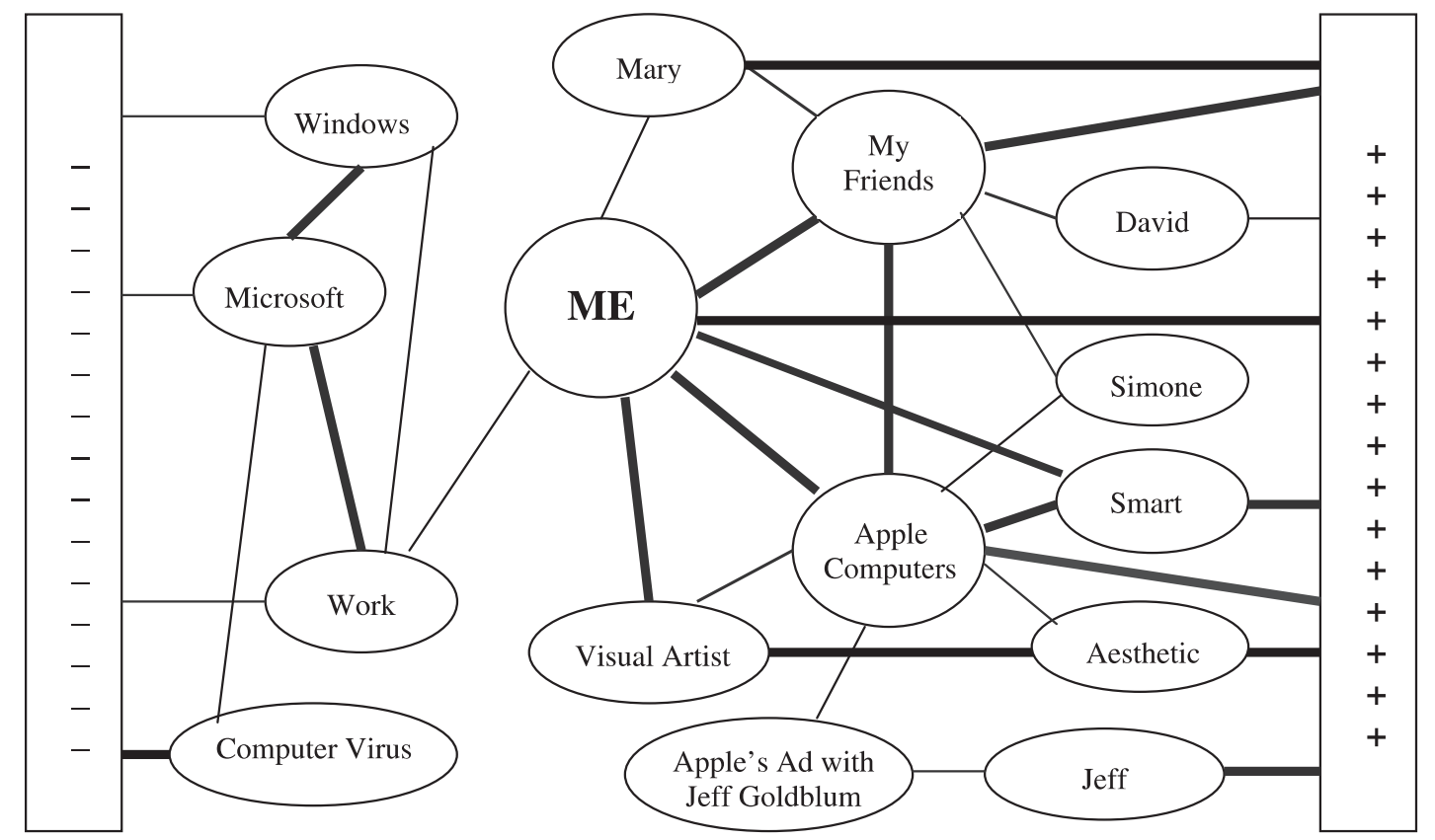

FIGURE 1 Hypothetical consumer social knowledge structure for a computer consumer. The consumer is at the center; the attribute, person, and group concepts are represented in the ovals. The positive and negative attribute valence concepts (two especially important attribute concepts) are represented by the + and - sign rectangles. The thickness of the links between concepts represents the strength of the automatic association between concepts. 
notes the strength of automatic concept associations. In this example, the consumer has a positive attitude toward Apple Computers based on positive associations with this concept (direct and indirect positive associations). Also, because Apple is directly linked to the concept of "self" and the association is strong, it can be assumed that there is a strong implicit brand identification or relationship. The opposite is true for the association with the competing brand, Microsoft, which is unrelated to self and has a negative valence.

A consumer social knowledge structure can also incorporate associations for brand image and brand personality. In our example, Microsoft's image is related to work (strong association) and computer viruses (weaker association) and Apple is perceived to have a smart personality. From a product management perspective, a consumer knowledge structure can capture implicit product perceptions and categorizations and can depict associations between products (e.g., complementarity, compatibility, or substitutability). It can also reflect associations between a consumer, a product, and a peer group. Figure 1, for example, shows that this consumer has a strong connection between Apple and her friends (in particular, Simone). Finally, connections between Jeff Goldblum (a strongly positively evaluated person in this case), an ad that features him as an Apple spokesperson, and the brand, could be a result of ad exposure and can show affect transfer (from the positive attitude toward the spokesperson, to attitude toward the ad, to brand attitude) and advertising effectiveness. Although Figure 1 does not provide an exhaustive account of all the consumer behavior constructs that might be found in a knowledge structure, it points out that this representation is flexible and comprehensive. The IAT provides a means to measure the relative strengths of the automatic associations between constructs in the structure (e.g., an assessment of implicit attitudes toward Apple versus Microsoft).

\section{Validity and Psychometric Issues}

Despite its conceptual and theoretical relevance, the general validity and reliability of the IAT must be assessed. Although the IAT has received rapid and extensive support (Devine, 2001), several issues remain to be addressed (for reviews, see Cunningham, Preacher, \& Banaji, 2001; Fazio \& Olson, 2003; Greenwald \& Farnham, 2000; Greenwald \& Nosek, 2001; Kihlstrom, 2004). In this section, we consider several specific issues and apply customary measurement criteria (Netemeyer \& Bearden, 1998) to the potential use of the IAT in consumer research. Finally, unresolved issues about the measurement technique are discussed.

Does the IAT correlate with explicit measures? A basic question concerns the relation between an IAT-based measure and its explicit counterpart. Ever since the early presentation of the IAT (Greenwald et al., 1998), researchers have claimed that IAT and self-report measures capture dis- tinct but correlated constructs (Greenwald \& Farnham, 2000). The constructs are typically related because of their common antecedents. Although the correlation between explicit measures and IAT is sometimes quite high (e.g., .69 in a 2000 presidential election IAT; Nosek, Banaji, \& Greenwald, 2002a), in other cases, it is low and not significant (Nosek \& Banaji, 2002). ${ }^{2}$ Still, the divergence of the constructs creates the potential for implicit and explicit measures to complement each other in predicting behavior (as observed by Maison et al., 2004).

It is nevertheless important to understand when IAT-based measures will be more or less correlated with their explicit counterparts. A review of empirical IAT findings suggests that the correlation between explicit and IAT measures can be limited by (a) response factors (e.g., inaccuracy in self-report due to impression management for sensitive questions or the type of object being assessed); (b) introspective factors (e.g., inaccuracy in self-reports because of respondents' poor introspection of their own attitudes or limited attitude elaboration); and (c) a lack of variance with some attitudes which can be homogeneous across a specific population (Greenwald \& Nosek, 2001; Nosek \& Banaji, 2002). The last argument is statistical in nature and the first two point out psychological factors. Consumer psychologists should consider how these moderating factors could be applicable in a consumer domain, and future research should aim at providing further empirical evidence of these effects and conditions.

Also related to this discussion are the issues of convergent and discriminant validity. First, IAT measures converge with semantic priming measures of association strength (Cunningham et al., 2001; Mellott \& Greenwald, 2000; Rudman \& Kilianski, 2000). Second, confirmatory factor analysis has shown discriminant validity of implicit and explicit self-esteem and gender self-concept (Greenwald \& Farnham, 2000). In addition, physiological measures (functional magnetic resonance imaging, or fMRI) have shown that IAT effects are linked to activation of the amygdala (a subcortical structure associated with emotional learning and evaluation) but not with other regions of the brain typically involved in explicit processing (Cunningham et al., 2003, Phelps et al., 2000). Evidence of this discriminant ability has been demonstrated in research showing that (a) prejudice against female job applicants was associated with IAT-assessed gender stereotypes, but not explicit gender stereotypes measures (Rudman \& Glick, 2001); or (b) even when impres-

\footnotetext{
${ }^{2} \mathrm{~A}$ correlation of .5 or more should be seen as high. It approaches the maximum value obtainable given the limitations imposed by unreliability of the component measures. For example, in a latent variable analysis (e.g., confirmatory factory analysis), the disattenuated correlation between implicit and explicit measures of the types used in these studies might be on the order of $r=.7$ (or even higher). In a setting of such purified measures, the variance not accounted for by a hypothesized implicit-explicit latent variable correlation (of 7 in this example) should be understood as real differences between the psychological constructs assessed by the two types of measures.
} 
sion management or inaccessibility are not a concern, IAT measures of attitude can explain variance in consumption behavior over and above that accounted for by explicit measures (Maison et al., 2004).

Is the IAT reliable? Test-retest reliabilities of the IAT average about .60 (Greenwald et al., 2002) and IAT measures have high internal consistency (alpha about equal to .80 and often higher; Greenwald \& Nosek, 2001). Also, the measure is resistant to several types of procedural artifacts. Specifically, the IAT effect is independent of (a) which hand is assigned to the pleasant category; (b) variability in the number of items used to represent categories; (c) the familiarity of the items used to represent categories (except for items with extremely low familiarity levels; Brendl, Markman, \& Messner, 2001; Greenwald \& Nosek; Rothermund \& Wentura, 2001); (d) variability in the response-stimulus interval; and (e) the order of the mixed categorization tasks (as long as there is counterbalancing of the order in the study; Greenwald \& Nosek). In addition, IAT effects have limited sensitivity to differences in how incorrect responses and nonnormal response latency distributions are treated (Greenwald \& Nosek).

Is the IAT sensitive to context effects? Based on a review of IAT research, Greenwald and Farnham (2000) concluded that "IAT measures can be influenced in theoretically expected fashion by procedures that might be expected to influence automatic attitudes or stereotypes" (p. 1023). For example, viewing photos of admirable members of stigmatized groups and despised members of nonstigmatized groups reduced implicit negative attitudes toward the stigmatized groups (Dasgupta \& Greenwald, 2000). Consequently, this sensitivity to situational and contextual manipulations requires further elaboration and explanation.

A special section of the November 2001 issue of the Journal of Personality and Social Psychology has explored these malleability and invariance issues. Although the implications of these articles are not unequivocal, they converge on the conclusion that the IAT should not be regarded as measuring a construct that is permanent or fixed (Devine, 2001). The IAT's susceptibility to these effects is not an indication of its failure to measure "stable" opinions. Indeed, because of its responsiveness to research manipulations, the IAT can be useful as a dependent measure, and it can be used to determine whether associations among specified concepts are consistent with theory. Besides, the IAT is less sensitive to instructions to fake than are explicit measures (Asendorpf, Banse, \& Mücke, 2002; Banse, Seise, \& Zerbes, 2001).

An explanation for the IAT responsiveness to contextual manipulations is that social concepts like male, female, African American, White, Asian, young., old, and so forth, exist not only as memory prototypes, but also as subtypes that may be different in valence from the prototypes. This is consistent with a multiple-systems view of memory where multiple bins encompass separate knowledge structures in long-term memory (Wyer \& Srull, 1989). The effect of a manipulation may be to activate a specific subtype (rather than the default prototype), which may then represent the larger category in the IAT. Certainly this explanation is consistent with the results obtained by Dasgupta and Greenwald (2000) that were discussed earlier. Further, respondents might not be aware of the factors that lead to the activation of a particular knowledge structure. Ultimately, future research on the specific theoretical underpinnings and processes of the IAT should provide greater understanding of this overall issue.

Does the IAT measure unconscious processes? Most generally, the IAT is assumed to measure association strengths. These association strengths can be given more specific interpretations, depending on the person's introspective access to them and the person's willingness to report them, as demonstrated by Greenwald et al. (2002) and Greenwald and Nosek (2001). If the association strengths are ones to which the person does not have introspective access, they can be called unconscious associations. It is also entirely possible that the person has access to them but prefers not to report them, in which case the IAT is measuring conscious association strengths that people do not wish to make public. Finally, when self-reported and IAT-measured associations agree, the question as to whether the IAT is measuring something conscious becomes inappropriate-the alternatives are not mutually exclusive.

A recent study by Forehand and Perkins (2003) provides evidence that the IAT can measure associations that occur outside of conscious awareness. They showed that the voice of a celebrity endorser only had a positive effect on implicit (IAT-based) attitudes toward the endorsed brand when the listener did not recognize the celebrity's voice in the radio ad (i.e., under unawareness condition). In this absence of conscious recognition (even on a cue-recall task), Forehand and Perkins made a case that the effect observed is due to an unconscious transfer of the spokesperson attitude to the brand attitude. When recognition was present, listeners became aware of the endorser's influence on their attitude, and cognitive responses (e.g., critical evaluation of the endorsement, evaluation of the match with the brand, counterargumentation, etc.) eliminated the endorser effect. This interaction effect with recognition, in conjunction with theoretical considerations, allows researchers to claim that associations were unconscious. Based on evidence from research in psychology and these recent findings in marketing, it is apparent that the IAT can be a measure of implicit consumer social cognition as well as an implicit measure of consumer social cognition.

Is the IAT sensitive enough to individual-level differences? The IAT can detect effects that are considered universal (e.g., preferences for flowers over insects; Greenwald et al., 1998), but also differences that vary between partici- 
pant populations. For instance, the IAT has identified differences between Japanese and Korean Americans' preferences for their own versus others' ethnicities (Greenwald et al., 1998), between East and West Germans' implicit attitudes toward their geographical regions (Kuehnen et al., 2001), and between men and women in both their implicit gender self-concepts (Greenwald \& Farnham, 2000) and their attitudes toward mathematics and the arts (Nosek, Banaji, \& Greenwald, 2002b).

Are there pitfalls involved in stimulus selection? A primary consideration in selecting stimuli is that they be reasonably familiar (although the IAT effect is robust across relatively wide variations in item familiarity), and unambiguously fall into one of two categories (e.g., pleasant vs. unpleasant, Nike vs. Reebok; Greenwald \& Nosek, 2001). The stimuli that are used to represent the various concepts and attributes in the IAT are either drawn from established category lists in the literature (e.g., Battig \& Montague, 1969; Bellezza, Greenwald, \& Banaji, 1986) or are selected on the basis of consensual familiarity and ability to be categorized easily and consistently. Both words and pictures can be used for target-concept or attribute dimensions.

A question arises as to whether the IAT measures associations at the category level or at the level of individual exemplars. Previous research supports the first possibility (De Houwer, 2001; Steffens \& Plewe, 2001). For example, British participants' answers to an IAT in which they were to categorize names of celebrities as either British or foreign were not affected by the affective evaluations of the exemplars used for the British (e.g., Princess Diana versus a notorious British person who was murdered) or foreign (e.g., Hitler versus Einstein) categories (De Houwer, 2001).

\section{Unresolved Concerns and Limitations}

The aforementioned discussion of the IAT has focused primarily on supporting evidence. A consideration of its limitations should be noted, however, in the context of assessing its potential usefulness for consumer research. First, the IAT only measures the relative strength of association. For example, it assesses the relative favorableness of a respondent's attitudes toward the two target objects being compared but not their absolute favorableness. Thus, a favorable IAT toward concept "A" versus "B" implies that "A" is preferred to "B." Yet, this could be true either because (a) the respondent likes "A" but is neutral toward "B," or because (b) the respondent is neutral toward "A" but dislikes "B." To this extent, the IAT assesses a comparative attitude (i.e., an implicit preference) rather than an attitude toward a single object.

One way to avoid this problem might involve a triangulation of the IAT effects with a known neutral or extremely polarized category, thereby disaggregating the relative preference in more absolute terms. Also, more direct approaches have been proposed. Methods derived from the IAT have been developed for single concepts, such as the Go/No-go Association Task (Nosek \& Banaji, 2001). Although this is a promising measure, it is still in the early stages of development and application, may not be as adaptive to the range of associations that the IAT can measure, and its psychometric properties are not yet as well reported as those for the IAT. Likewise, priming measures do not have the IAT's limitation of being a relative measure. For example, relative to a neutral baseline that might be provided by the absence of a prime (or use of a presumably neutral prime), faster responding to positive targets in the presence of a prime indicates that the prime is more strongly associated with positive than with negative evaluation. In addition, the priming procedure may allow the assessment of evaluative associations of individual words, whereas the IAT assesses evaluations at the level of the category to which a group of words belongs. However, as discussed earlier, priming measures have relatively inferior psychometric properties.

The IAT might not be a very efficient measure if one is interested in concepts that can be measured explicitly. There is little justification for the use of a complex procedure if a similar outcome can be obtained through a questionnaire. The IAT will be especially useful in situations in which it can predict variations in consumer behavior beyond those explained by parallel explicit measures.

Other criticisms have been levied against the IAT. Some have suggested that response patterns from the IAT may be confounded with other factors such as a person's cognitive ability (McFarland \& Crouch, 2002) or respondents' shift in response criterion during the difficult or incompatible mixed block of the test (e.g., "insects" with "pleasant;" Brendl et al., 2001). Brendl et al. argued that the difficulty of the classification task (rather than just the underlying attitude) might confound IAT findings in some situations. Others have argued that the IAT might also capture an attitude object's environmental or cultural associations instead of just one's evaluation of the object (Karpinski \& Hilton, 2001). Finally, it is worth noting that advances in the development of the IAT have been driven largely by a concern with measurement issues. A stronger theoretical model of the components of IAT effects is necessary to understand better how the IAT measures association strength and whether it captures more than association strength.

\section{Summary}

Earlier in the article, we argued that consumer psychologists would benefit from implicit measures that display convergent validity, are sensitive to individual differences, and are insensitive to image management and attitude accessibility differences. The IAT is not a "finished" product and there are still some psychometric, validity, or procedural questions that future research should address. Based on this evidence, however, the IAT satisfies the aforementioned measurement criteria and possesses properties that are superior to priming 
techniques (e.g., superior test-retest reliability and greater sensitivity to individual differences). Further the IAT should be superior when predictions are at the category level, whereas priming may offer some benefits at the exemplar level (Fazio \& Olson, 2003). The next step is to provide direct empirical support for its validity and value in consumer research.

\section{RESEARCH SYNOPSIS}

In the empirical section of this article, we use the IAT to measure consumer-related constructs (e.g., brand attitudes, brand relationships, and attitudes toward an ad). As previously discussed, attitudes can be represented as the association between an attitude object and a valence attribute concept (Greenwald et al., 2002). In addition to evaluative assessments, consumers can also have deep relationships with a brand, with the brand becoming part of a person's self-concept (Belk, 1988; Fournier, 1998; Kleine, Kleine, \& Allen, 1995). Study 1 tests the validity and usefulness of the IAT for measuring these constructs across two real brands. In Study 2 , the IAT is used to capture implicit Aad by measuring the relative strength of the association between advertisements with spokespeople of different ethnicities and the valence attribute concepts (pleasant vs. unpleasant). Although Study 1 demonstrates the convergent validity of the IAT in a consumer setting, Study 2 shows that the IAT can also reveal dissociations between explicit and implicit consumer social cognition. In a follow-up study, we also eliminate alternative explanations for our results and demonstrate that the IAT effect is derived from consumers' relative evaluations of the categories, and not the exemplars used to operationalize the categories.

\section{STUDY 1}

Study 1 was designed to test the efficacy of the IAT as a measure of brand attitudes and brand relationship strength. To do so, we chose a topic where implicit and explicit attitudes were expected to converge. Computer platforms (more specifically, Macintosh [Mac] and Microsoft Windows-based [PC] machines) were chosen as the focal targets. We did not expect significant differences between explicit and implicit attitudes because consumers are likely to know their attitudes toward the target and to lack the motivation to disguise them. This study was also designed to test the IAT's utility in measuring consumer-brand relationships (i.e., the degree to which a brand is part of a consumer's self-concept). In this regard, we expected that Mac users would have a stronger relationship with their preferred brand than would PC users, as they often see themselves as part of a close community of users who have strong ties to the product (Muniz \& O'Guinn, 2001).

\section{Method}

Procedure and design. Eighty-eight introductory psychology students participated in the study on a voluntary basis for extra course credit. For each participant, data were collected in two locations (a common room where paper-and-pencil questionnaires were administered and four individual rooms where the IAT measures were administered). Fifty-six students participated and provided data that could be matched across the two parts of the study. In the first half of the study, participants completed a three-page survey with demographic, vision, and computer proficiency questions, explicit measures of Mac versus PC attitudes, computer ownership, and usage frequency. Prior research has demonstrated that the order of implicit versus explicit measures has inconsequential effects on the results (Greenwald $\&$ Farnham, 2000). We nevertheless selected the most conservative option and captured the explicit measures first because the IAT is less likely than explicit measures to be influenced by prior measures.

In the second half of the study, participants completed two IATs in counterbalanced order. One IAT, which consisted of the stimulus sequence shown in Figure 2, measured implicit attitudes by using stimuli representing Mac and PC computers (the target concepts) and pleasant and unpleasant words. The other IAT measured implicit brand relationships by pairing the Mac and PC-related stimuli with words representing the concepts "self" and "other" rather than pleasantness-related words. Self-related words included "I," "me," "my," and "mine;" other-related words included "they," "them," "their," and "other."

The first IAT we administered consisted of 7 blocks with 32 trials during the practice blocks and 40 trials during the measured blocks. Each trial consisted of the presentation of a single stimulus item. The second IAT only required six blocks (the block in Step 1 of Figure 2 was unnecessary for the second IAT as the Mac versus PC categorization had already been practiced and the key assignments remained unchanged for each participant). Participants were randomly assigned to one of eight counterbalanced task orders to accommodate three procedural factors (i.e., a $2 \times 2 \times 2$ design): whether the brand attitude or brand relationship IAT was administered first, whether pleasant or unpleasant were initially assigned to the left or right key (in other words, presentation order of the favorable versus unfavorable attitude), and whether self or other were initially assigned to the left or right key.

Measures. During the IAT, the computer recorded participants' response latencies (in milliseconds) for the two measured blocks. Trial number, block, stimuli information, and error rates were also recorded. Consistent with prior procedures and recommended guidelines established for the IAT (Greenwald \& Farnham, 2000; Greenwald et al., 1998), the first two trials in the measured blocks were 


\section{CATEGORY LABELS SAMPLE STIMULI CATEGORY LABELS}

Step 1:

Practice

block

(32 trials)

\begin{tabular}{|c|c|c|}
\hline Apple/Macintosh & & PC-type/IBM \\
\hline & MACINTOSH & 要 \\
\hline 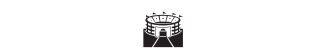 & 堆且 & \\
\hline
\end{tabular}

Step 2:

Practice

block

(32 trials)

\begin{tabular}{|c|c|c|}
\hline Pleasant & & Unpleasant \\
\hline & LUCKY & 要究 \\
\hline 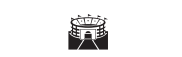 & HATRED & \\
\hline
\end{tabular}

Step 3:

Practice block (32 trials)

Measurement

block

(40 trials)

\begin{tabular}{|c|c|c|}
\hline $\begin{array}{c}\text { Apple/Macintosh } \\
\text { or } \\
\text { Pleasant }\end{array}$ & & $\begin{array}{c}\text { PC-type/IBM } \\
\text { or } \\
\text { Unpleasant }\end{array}$ \\
\hline & HONOR & \\
\hline & WINDOWS & \\
\hline & DISASTER & \\
\hline & & \\
\hline
\end{tabular}

Step 4:

Practice

block

(32 trials)

\begin{tabular}{|c|c|c|}
\hline Unpleasant & & Pleasant \\
\hline 箱 & LOVE & \\
\hline & VOMIT & 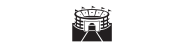 \\
\hline
\end{tabular}

Step 5:

Practice block (32 trials)

Measurement block

(40 trials)

\begin{tabular}{|c|c|c|}
\hline $\begin{array}{c}\text { Apple/Macintosh } \\
\text { or } \\
\text { Unpleasant }\end{array}$ & & $\begin{array}{c}\text { PC-type/IBM } \\
\text { or } \\
\text { Pleasant }\end{array}$ \\
\hline 覆 & FREEDOM & \\
\hline \multicolumn{3}{|l|}{ 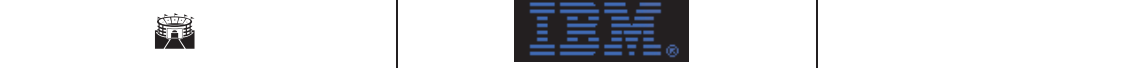 } \\
\hline & SICKNESS & 餖 \\
\hline & Apple & 蛪輁 \\
\hline
\end{tabular}

FIGURE 2 Schematic description of the Implicit Attitude Test (IAT; adapted from Greenwald \& Farnham, 2000). The correct response for each sample stimulus is indicated by a check mark. The IAT effect is calculated as the difference in average response latencies between the two measurement blocks in steps 3 and 5. Complete stimuli included six words for each of the pleasant and unpleasant categories, and five words or pictures for each of the Apple/Macintosh and PC-type/IBM categories. 
dropped because they are typically longer; latencies longer than 3,000 msec were recoded to $3,000 \mathrm{msec}$, and latencies shorter than $300 \mathrm{msec}$ were recoded as $300 \mathrm{msec}$. After the data transformations, the IAT effect was calculated as the difference in average response latencies between the third and fifth step depicted in Figure 2. A pro-Mac implicit attitude effect occurred when a participant was quicker to categorize a stimulus when Mac and pleasant shared the same response key compared to when Mac and unpleasant shared the same key. A self-Mac implicit brand relationship effect occurred when a participant was quicker to categorize Mac and self together compared to Mac and other. Higher scores on the IAT effects described in this study indicate more favorable implicit attitude and brand relationship toward Mac relative to $\mathrm{PC}$.

Explicit attitudes toward Mac and PC were measured in the survey along a 5-item, 7-point semantic differential scale, anchored by good-bad, pleasant-unpleasant, inferior-superior, unsatisfactory-satisfactory, and favorable-unfavorable ( $\alpha=.90$ for both Mac and PC scales). Two ownership measures (Mac and PC) asked participants to indicate how many computers of each type they owned. For each brand, usage frequency was measured with 9-point semantic differential scales anchored by not at all-very frequently. Participants' scores on the explicit attitude, ownership, and usage measures for PC were subtracted from their Mac scores to generate a relative measure of Mac versus PC tendencies. Consistent with the IAT effect, higher scores on these measures indicated a greater preference for Mac versus PC.

\section{Results}

Initial analyses tested the effects of the three counterbalancing factors (e.g., order of the two IATs). None of these factors had a significant effect on the IAT results. These null findings are consistent with prior studies using the IAT demonstrating the robustness of the IAT across several procedural variations (Greenwald et al., 1998; Greenwald \& Nosek, 2001). Therefore, the analysis that follows is collapsed across the eight procedural conditions.
A primary concern of this study is the degree to which the explicit measures of brand attitudes, ownership, and usage were correlated with IAT-based measures of implicit brand attitudes and brand relationship. Table 1 illustrates that all of the explicit difference measures were significantly positively correlated with the IAT-based measures. Thus, under conditions in which participants were not expected to hide their beliefs, explicit brand attitudes were strongly correlated to implicit attitudes $(r=.50, p<.01)$ and implicit brand relationship ( $r=.54, p<.01)$, thereby validating the IAT for brand evaluation. Further, both IAT-based and explicit brand attitudes were also strongly correlated ( $r=.69$ for both cases) with explicit usage measures.

Individual differences in attitude. Additional analysis was conducted to investigate differences in IAT-based measures between pro-Mac and pro-PC respondents. To do this, the explicit difference scores for attitude, ownership, and usage were dummy-coded. Participants who had reported more favorable Mac explicit attitudes, ownership, or usage were assigned a 1, whereas those who had reported more favorable reactions to PC-related measures were assigned a 0. Participants who were indifferent (that is, whose scores on the attitude, ownership, and usage measures were the same for PCs and Macs) were excluded from this analysis. This eliminated $11.4 \%, 20.3 \%$, and $5.6 \%$ of the participants who reported equivalent attitudes, ownership, and usage, respectively (note, however, that only the size and not the direction of the effects changes if the ambivalent respondents are also kept in the analysis).

Participants who reported more favorable explicit attitudes, greater ownership, or usage frequencies for a brand had significantly faster response latencies when the brand was paired with "pleasant" versus "unpleasant," thereby yielding consistency between the implicit and explicit constructs. The difference was statistically significant in all six comparisons (see Figure 3). Thus, implicit brand attitudes were correlated with explicit brand preferences but also were sensitive to individual behavioral differences. Further, a comparison of implicit attitude effects for PC versus Mac

TABLE 1

Correlations Among Key Variables-Study 1

\begin{tabular}{|c|c|c|c|c|c|c|c|c|}
\hline \multirow[b]{2}{*}{ Pearson Correlation } & \multicolumn{2}{|c|}{ Implicit Attitude } & \multicolumn{2}{|c|}{$\begin{array}{l}\text { Implicit Brand } \\
\text { Relationship }\end{array}$} & \multicolumn{2}{|c|}{$\begin{array}{c}\text { Explicit Brand } \\
\text { Attitude } \\
\text { (Difference Score) }\end{array}$} & \multicolumn{2}{|c|}{$\begin{array}{c}\text { Computer } \\
\text { Ownership } \\
\text { (Difference Score) }\end{array}$} \\
\hline & $n$ & $\%$ & $n$ & $\%$ & $n$ & $\%$ & $n$ & $\%$ \\
\hline Implicit brand relationship & 63 & $.542 * *$ & & & & & & \\
\hline Explicit brand attitude (difference score) & 54 & $.504 * *$ & 54 & $.307 *$ & & & & \\
\hline Computer ownership (difference score) & 54 & $.468 * *$ & 54 & $.411 * *$ & 79 & $.581 * *$ & & \\
\hline Computer usage & 50 & $.688 * *$ & 50 & $.543 * *$ & 72 & $.692 * *$ & 72 & $.689^{* *}$ \\
\hline
\end{tabular}

Note. High scores on the Implicit Association Test and the explicit difference scores indicate preferences for Macintosh relative to Microsoft Windows-based PC-type computers.

$* p<.05$. ** $p<.01$. 

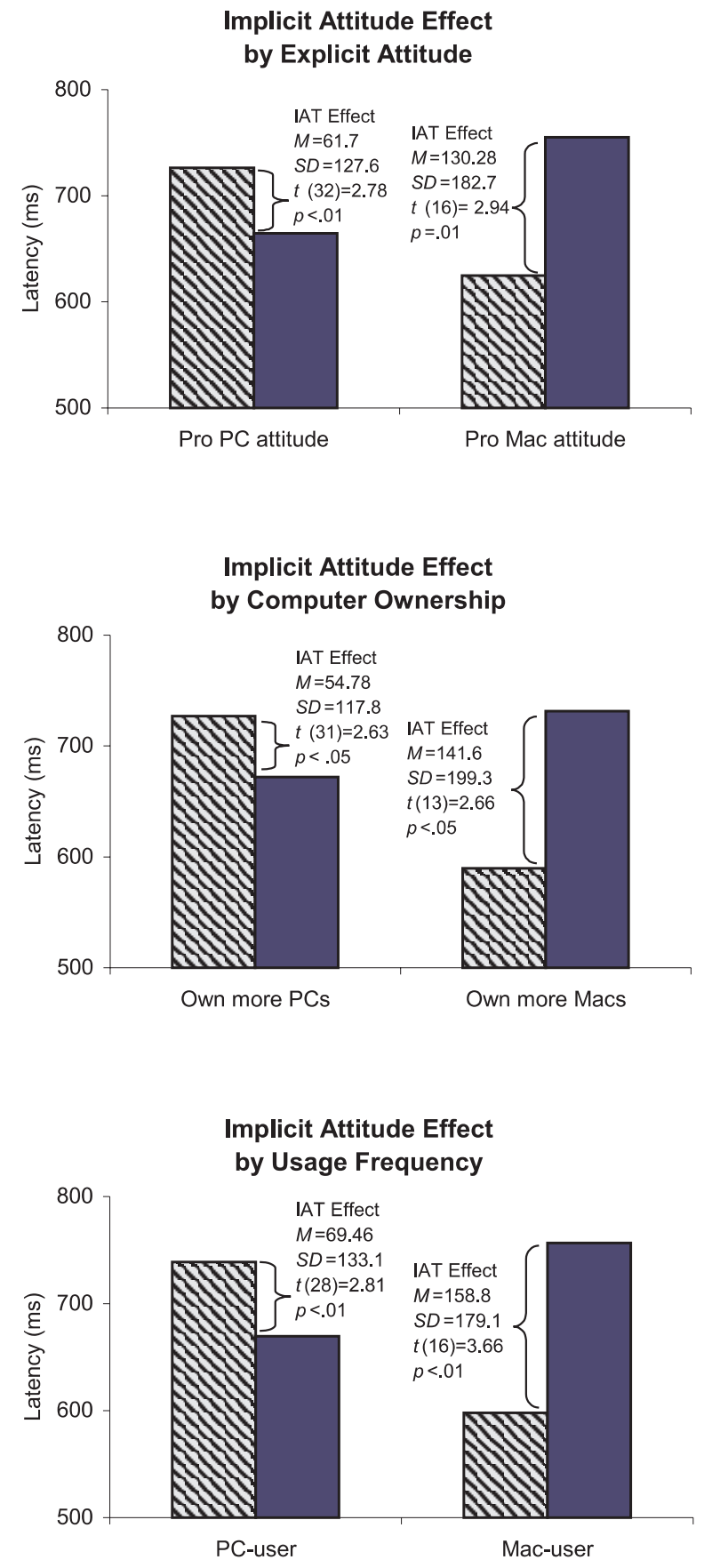

Mac \& pleasant words
Implicit Brand-Relationship Effect

by Explicit Attitude

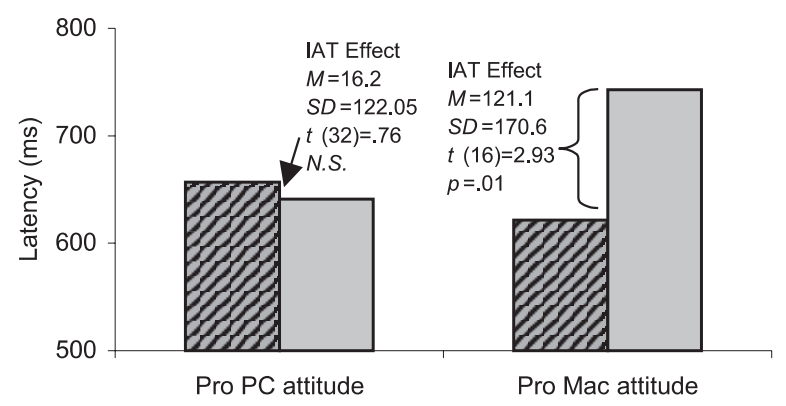

Implicit Brand-Relationship Effect by Computer Ownership

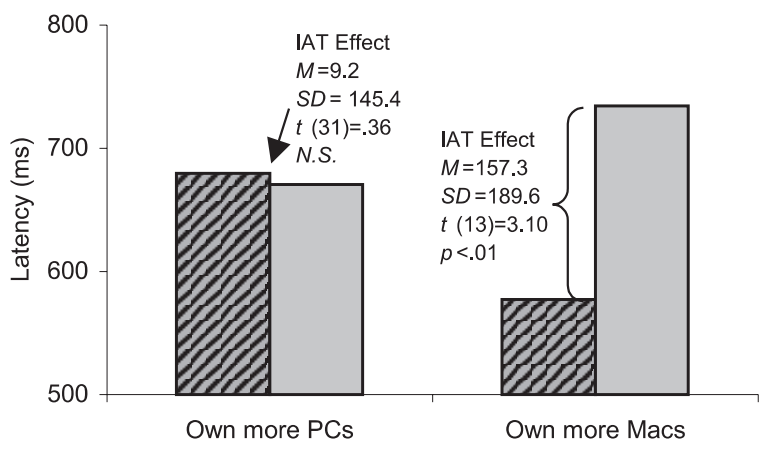

Implicit Brand-Relationship Effect by Usage Frequency

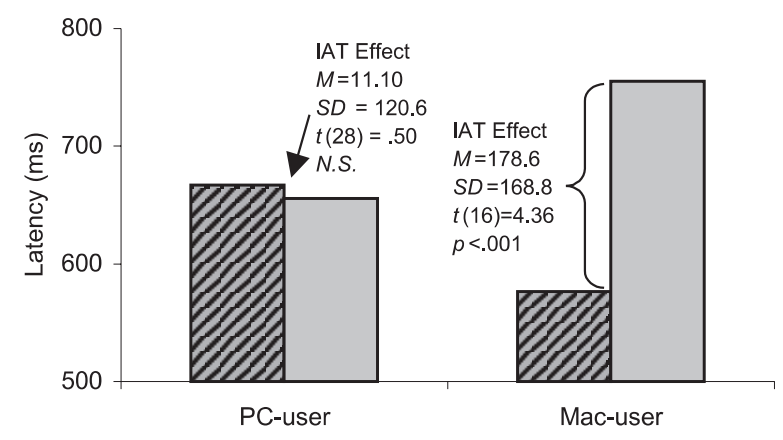

PC \& pleasant words Mac \& Self words 
loyalists yielded stronger IAT effects for the Mac groups than the PC groups. Whether the data were split by prior attitude, ownership, or usage, the average IAT effect for the Mac loyalists ranged from 130.28 to $158.8 \mathrm{msec}$, but ranged only from 54.78 to $69.46 \mathrm{msec}$ for the PC group $(t>4.18, p<.001$, for all three comparisons). These results indicate that attitude strength and accessibility were consistently greater for Mac loyalists than for PC loyalists.

Individual differences in brand relationships. A significant IAT brand relationship effect was only evident for the Mac loyalists, $M=121.1, t(16)=2.93, p=.01$, for explicit attitude; $M=157.3, t(13)=3.10, p<.01$ for ownership; $M=$ $178.6, t(16)=4.36, p<.001$, for usage; see Figure 3). Participants who reported more favorable explicit attitudes, greater ownership, or usage frequencies for Mac had significantly faster response when Mac and self were combined as opposed to Mac and other. Conversely, PC loyalists' response latencies when PC and other were combined as opposed to $\mathrm{PC}$ and self were not different ( $t$ values ranging from .36 to .76). Further, a comparison of implicit brand relationships for PC versus Mac loyalists confirmed stronger IAT effects for the Mac groups than the PC groups. Whether the data was split by prior attitudes, ownership, or usage, $t$ tests confirmed higher IAT effect for the Mac group than for the PC group ( $t>$ $3.25, p<.005$, for all three comparisons). Together, these results suggest that owning a Mac is closely related to one's implicit identity whereas owning a PC is not.

\section{Discussion}

This study demonstrates the validity of the IAT as an instrument for measuring implicit brand attitudes and brand relationships. First, in a situation where implicit and explicit constructs would be expected to converge, IAT measures of brand attitude and brand relationship were strongly correlated with explicit measures of brand attitude, ownership, and usage. Furthermore, IAT measures effectively differentiated consumers who reported more favorable explicit attitude, ownership, and usage of one brand versus the other. Second, the measurement benefits of the IAT are particularly compelling with respect to brand relationships. In Fournier's (1998) terms, Mac users appeared to have a stronger self-connection to the brand than did PC users. The strong Mac brand relationship might stem from the resistance and loyalty that Mac users have developed after years of being a small share in the computer world (Wong, 2001) and the strong sense of brand community exhibited by Mac users (Muniz \& O'Guinn, 2001). Because of their minority status, Mac users may hold "a socially embedded and entrenched loyalty, brand commitment... and even hyper loyalty" (Muniz \& O'Guinn, p. 427). The IAT results also confirm that brands "serve as powerful repositories of meaning purposively and differently employed in the substantiation, cre- ation, and (re)production of concepts of self in the marketing age" (Fournier, p. 365).

\section{STUDY 2}

The previous study showed that IAT-based measures of brand attitudes and relationships are correlated with explicit measures when consumers have access to their attitudes and are willing to share them. This validation of the IAT in a marketing context was a necessary step in establishing that the IAT is a valid marketing measure. This step is also imperative if one is to show that under other conditions, there can be dissociations (i.e., no significant correlations) between explicit marketing attitude measures and corresponding IAT measures. Study 2 provides this demonstration, showing that the IAT can uncover consumers' attitudes that traditional measures do not detect. In doing so, it demonstrates that explicit measures can lead to erroneous conclusions if implicit measures are not considered.

In this study, we investigated the topic of the race of advertising spokespeople. Past IAT research has shown that the IAT reveals racial biases that explicit measures do not detect (Dasgupta \& McGhee, 2000; Greenwald et al., 1998). Also, there is an extensive body of research dealing with the impact of spokespeople on ad persuasion (e.g., Deshpande \& Stayman, 1994; Heath, McCarthy, \& Mothersbaugh, 1994; Kamins, 1990). This latter research, however, has been based on explicit measures (c.f. Forehand \& Perkins, 2003, for an exception). In Study 2, we focus on attitudes toward the ad (Aad; see Brown \& Stayman, 1992, and Mitchell \& Olson, 1981, for reviews on this topic) and show that the IAT can detect negative racially biased Aad evaluations for respondents that provide socially acceptable answers in explicit measures.

\section{Method}

Procedure and design. Ninety-three undergraduate students studying introductory business statistics (consisting of 33 men: 46 Whites, 30 Asians, 6 Hispanics, 6 African Americans, 5 multiracial or other ethnicities; median age = 19), participated in the study for course credit. Data for each participant were collected during a single experimental session lasting under $45 \mathrm{~min}$. As before, explicit measures were collected first. Participants completed a survey containing demographic, vision, and computer proficiency questions. Subsequent analysis showed that all participants could be retained in the sample. The survey also included measures of the key construct of interest-attitude toward the ad (5-item scale) — both for ads with White spokespeople and ads with Black spokespeople. Measurement order was counterbalanced, so that half of the participants reported their attitudes toward ads that featured White spokespeople first and the other half reported attitude toward ads with Black spokespersons first. Participants were randomly assigned to 
one of the orders. Then, participants completed a 7-block computer-based IAT. Blocks 4 and 7 were the measurement blocks (counterbalanced as well). Each block consisted of 32 (practice) and 40 (measured) trials each. In addition to trial number, block number, and stimuli information (see the Appendix for examples of the stimuli), participants' response latencies (in milliseconds) and error rates were recorded.

Stimuli. For this study, we developed 32 ads. These ads had a simple layout to allow for quick processing and classification. They consisted of an athlete's picture (male or female) and a brand identifier (name or logo). Based on a brand familiarity pretest for 20 brands and with participants from the same target population, ads were designed for two different athletics footwear brands: an unfamiliar brand-Etonic (no participants reported owning Etonic shoes and the brand received a 6.72 familiarity rating-where $1=$ very familiar and $9=$ very unfamiliar ) and a familiar brand - New Balance (35\% of participants reported owning a pair of New Balance shoes, and they gave the brand a 2.70 familiarity rating on the same scale). We purposely avoided using "megabrands" such as Nike, Addidas, or Reebok. Sports were varied, and included tennis, basketball, track, golf, and bodybuilding. Four ads were constructed for each sport: one with a White athlete and a matching one with a Black athlete (none were celebrities), for each of the two brands ( 32 ads in total: 8 sports $\times 2$ races $\times 2$ brands). Efforts were made to insure that the Black and White race versions of the ads matched each other (see the Appendix for stimuli examples-faces of the models are masked in this appendix, but were visible to the respondents). To minimize differences across ads, they were displayed in black and white mode. This study used the same list of pleasant and unpleasant words that were used in Study 1.

Measures. Explicit measures of Aad were collected for both ads with White spokespersons and ads with Black spokespersons. This was done using a 6-item semantic differential scale (interesting-boring, good-bad, pleasant-unpleasant, like-dislike, favorable-not favorable, irritating-not irritating). These items have been used in past research on Aad (MacKenzie \& Lutz, 1996; MacKenzie, Lutz, \& Belch, 1986; Mitchell, 1986; Mitchell \& Olson, 1981). Scale reliability was high: $\alpha($ Black $)=.93 ; \alpha($ White $)=.88$. An explicit Aad preference was created by taking the difference in score between Aad White minus Aad Black.

Implicit Aad was measured using a similar methodology to Study 1. In this study, the IAT effect was measured as the difference in average response latencies in the blocks when the classification target category (ad with a Black spokesperson versus ad with a White spokesperson) shared the same response key as the attribute concept ("unpleasant" vs. "pleasant"). Thus, a pro-White spokesperson implicit Aad effect occurred when a participant was quicker to categorize stimuli when ads with a White spokesperson shared the same re- sponse key with "pleasant" than when they shared the same key with "unpleasant."

\section{Results}

Explicit and implicit attitudes toward the ads are shown in Figure 4. As expected, there were no significant differences between explicit attitudes toward ads with White spokespersons, $M=4.67$, compared to ads with Black spokespersons, $M=4.77, t(92)=-1.32$, ns (see Figure 4), suggesting that at the explicit level, participants did not exhibit racial preferences. However, implicit measures of Aad revealed a strong preference for ads containing White spokespersons: IAT effect, $M=244.53 \mathrm{msec}, t(92)=11.25, p$ $<.001$. Also, the implicit and explicit measures of ad preferences were not significantly correlated $(r=.135, p>.3)$. This dissociation between the implicit and explicit results is further confirmed by a significant interaction of race of the spokesperson and measurement method in an analysis of standardized attitude scores, $F(1,92)=146.93, p<.001$.

In this subsequent analysis, we considered responses from White and Black participant subgroups. As shown in Figure 5 , the subgroups exhibited divergent results. White respondents exhibited a significant "pro-White" IAT preference, $M$ $=255.70 \mathrm{msec}, t(45)=14.99, p<.001$, but no significant explicit preference. The Black group indicated preferring ads with Black spokespersons at the explicit level, $M=0.75, t(5)$ $=3.40, p<.05$, but no significant implicit preference. Further, the IAT preference for ads with White spokespersons was significantly greater for White respondents, $M=255.70$ msec, than for Black respondents, $M=22.92 \mathrm{msec}, F(1,50)$ $=9.85, p<.005$; whereas the explicit preference for ads with Black spokespersons was significantly greater for Black respondents, $M=0.78$, than for White respondents, $M=0.01$, $F(1,50)=7.11, p<.01$.

Further analysis confirmed that there was a significant interaction of ethnicity and measurement method on the revealed preference for "ads with spokespersons of one's own

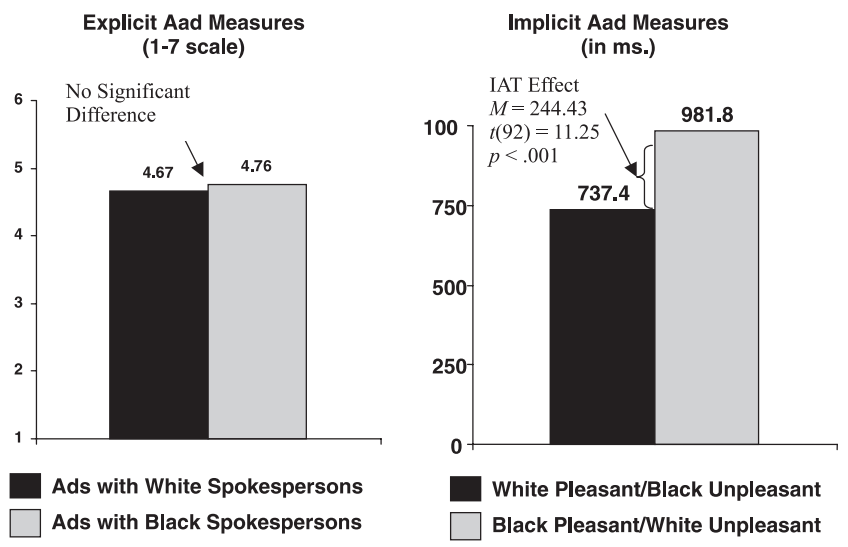

FIGURE 4 Overall explicit and implicit attitudes toward the ad-Study 2. 

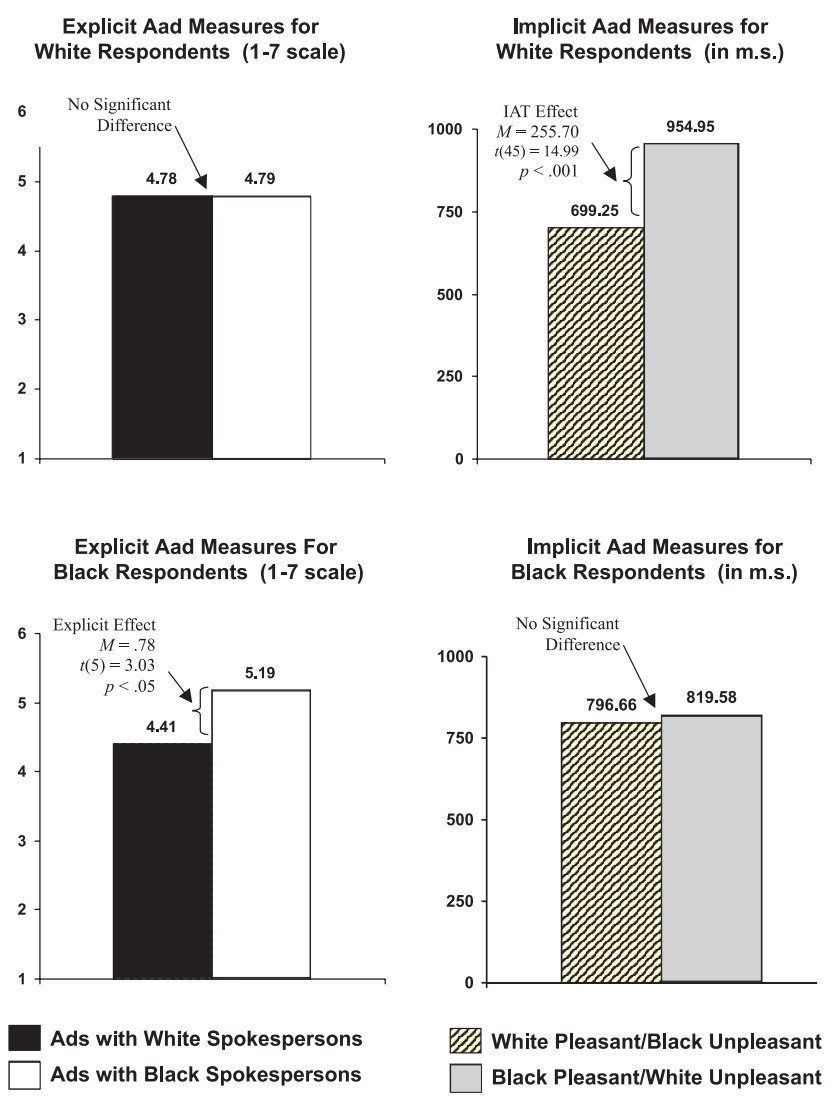

FIGURE 5 Explicit and implicit attitudes toward the ad as a function of respondent ethnicity-Study 2 .

ethnicity," $F(1,50)=21.96, p<.001$. The results depicted in Figure 6 are based on standardized scores to account for the unit difference between the two measures. The findings show that White respondents did not acknowledge an explicit preference $(M=-0.02)$, but implicitly preferred their in-group $(M=1.38)$. Conversely, Black respondents revealed an in-group preference at the explicit level $(M=1.11)$ but not at the implicit level $(M=-0.12)$.

\section{Follow-Up Study}

To further probe the validity of Study 2 results, we conducted supplemental data analysis and collected additional data in a follow-up experiment. Our main goal was to assess the extent to which our results might have been influenced by the stimuli used. We first conducted an additional analysis of the aforementioned results to show that brand effects did not confound the findings. We compared the average latencies for classification of the brand stimuli (excluding the pleasant-unpleasant stimuli) and found that there was no brand effect on implicit Aad, $F(1,185)<1$. Although this null result is noteworthy, it is important to show that the absence of brand effect was driven by the task (i.e., the respondents were

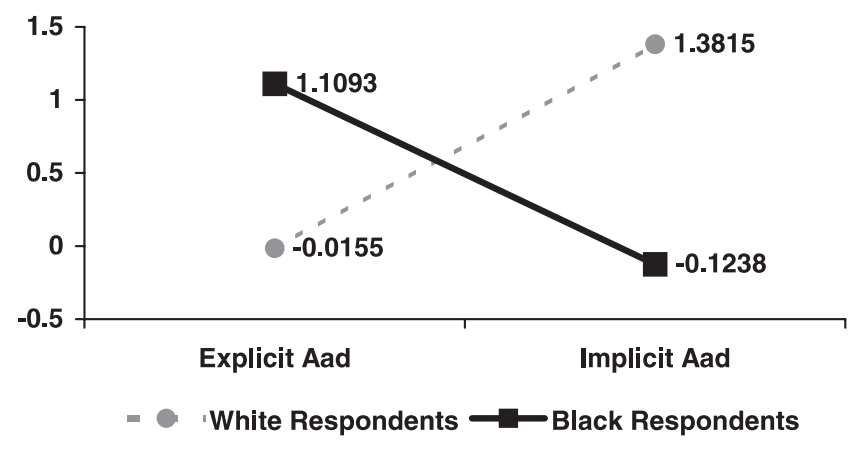

FIGURE 6 Standardized preferences for ads with spokespersons from own ethnicity as a function of respondent ethnicity and measurement method-Study 2. A positive number indicates a preference for ads with spokespersons from one's own ethnic group. Zero indicates equal preference for ads with White or Black spokespersons. A negative number indicates preference for ads with spokespersons from the opposite ethnic group.

focused on the race of the spokesperson classification task) rather than by an overall absence of brand preference.

We therefore designed a follow-up IAT experiment using the same stimuli as before, but asked new participants to classify the ads based on the brand (Etonic vs. New Balance). Fifty-four respondents from the same participant pool participated. They matched the first sample in terms of demographics. The IAT effect was significant, $M=125.52 \mathrm{msec}$, $t(53)=5.45, p<.001$, showing an overall preference for New Balance over Etonic. However, the IAT effect was not contingent on the race of the spokesperson, $F(1,107)<1$.

\section{Discussion}

Study 1 demonstrated the validity of the IAT as a measure of implicit brand attitudes and brand relationships, showed correlations with explicit measures, and established its individual level sensitivity. Conversely, Study 2 showed that the IAT is also a useful measurement for testing effects that explicit measures do not uncover. In this regard, explicit measures of Aad may have reflected views that participants wished to present (i.e., a potential distortion to avoid violating social norms; see Demo, 1985; Dovidio \& Fazio, 1992), whereas the implicit measures reflected more uncontrollable automatic associations. For example, White respondents evidenced an implicit preference for ads with White spokespersons, suggesting that the absence of difference at the explicit level can stem from a desire for social correctness.

Also, the Black group showed a lack of implicit in-group preference, in a manner consistent with System Justification Theory (Jost \& Banaji, 1994). This theory predicts that low status groups are more likely to internalize and accept their condition and this can lead to in-group devaluation. Although not always measurable explicitly, this phenomenon is more likely to be picked up by implicit measures like the IAT (Rudman, Feinberg, \& Fairchild, 2002). In Study 2, Black re- 
spondents showed a favorable explicit Aad for ads featuring their in-group, yet they also displayed an automatic response with no positivism for their in-group. This devaluation of one's in-group increases as the status of the minority group decreases so that the lower the status of a minority group, the lesser the automatic preference for one's in-group (Rudman et al., 2002). In the case of very low status groups, this implicit acceptance of social prejudice can even lead to more favorable associations with the out-group (Rudman et al., 2002). We would not expect Black students at a major university to display such an extreme in-group bias. It is nonetheless striking that their automatic associations suggested a lack of preference for their own group.

Finally, the supplementary data obtained in this study confirm the assumption that the IAT operates at the category level as suggested by previous research, and that evaluations of specific stimulus exemplars (e.g., liking New Balance) have no detectable effects when the classification task refers to the race of the spokesperson, and vice-versa. This is particularly helpful if one is concerned with isolating the associations for one concept, as it appears that as long as the categorization is clear, results should be resilient to exemplar level effects.

\section{GENERAL DISCUSSION}

In this article, we have reviewed the strengths and limitations of the IAT as a metric for investigating implicit consumer social cognition. In addition, we provided an empirical examination of the IAT's validity and individual-level sensitivity in the implicit measurement of brand attitude, consumer-brand relationship strength, and attitude toward the advertisement (Aad). Finally, we showed that the IAT is able to detect consumer behavior effects that explicit measures could not. Our review of the literature and two studies permits several conclusions.

First, explicit measures and IAT measures of attitudes and other marketing constructs converge when consumers are willing and able to report their feelings and beliefs. This convergence was clearly evident in Study 1, where social desirability or other biases were not likely to occur. However, IAT-based measures of brand relationship strength revealed distinctive asymmetries between brands, demonstrating that the IAT can measure other constructs besides attitudes. Study 1 also showed that the IAT was sensitive to individual differences in attitude accessibility and strength.

Second, the IAT can also capture automatic associations between target concepts and attribute dimensions that are distinct from explicit measures. In Study 2, IAT-based measures of Aad revealed an influence of ethnic preference on Aad that explicit measures did not. These findings underscore the potential utility of the IAT in gaining a better understanding of the impact of ethnic stereotypes on advertising and brand attitudes.

As discussed earlier, research on the role of unconscious processes in consumer learning seems to be a logical candidate to benefit from the IAT in the near term. Research on Aad formation, mere exposure effects, and classical conditioning (e.g., Janiszewski, 1988), could also use the IAT to determine if automatic or implicit associations between brands, ads, and attribute dimensions, behave as would be expected by these theories. Instead of relying on a lack of recall or other conscious processes as evidence that preconscious activities are present, the IAT can allow researchers to tap directly into the implicit associations that are presumed to occur.

Unconscious and automatic processes should also be considered in other consumer behavior domains. The IAT could provide valuable measures of controversial or stigmatized topics. Past research investigating the impact of stigmas associated with volunteerism (Snyder, Omoto, \& Crain, 1999) has shown that the public stigmatizes people who engage in socially beneficial activities such as volunteering to help someone with AIDS. The IAT could potentially be used to expose the associations that drive these perceptions, such as an association between AIDS and homosexuals, drug users, and other stigmatized groups. Similarly, the IAT could be used to investigate how negative events that involve spokespeople can impact attitudes toward the spokespeople and the brands they represent (Louie, Kulik, \& Jacobson, 2001). In both cases, the IAT might uncover the automatic associations between attitude objects and stigmatized attributes.

Our results can be linked to other research on race and ethnicity in marketing. For example, research on consumer distinctiveness and ethnic self-awareness (Forehand \& Deshpande, 2001; Grier \& Deshpande, 2001) has examined the effect of spokesperson ethnicity and other ethnic primes on brand attitudes and persuasion. This research has discussed the presence of "unconscious ethnic processing and categorization" (Forehand \& Deshpande, p. 338). Therefore, it seems that IAT-based measures of implicit ethnic stereotypes, Aads, and brand attitudes, could allow further advances in this area. Certainly it is not our intent to suggest that because the IAT showed that White respondents had "pro-White" implicit attitudes, marketers should avoid using minorities in their ads. Indeed, marketing has long recognized the value of Michael Jordan, Tiger Woods, or the Williams sisters as spokespeople. However, greater understanding of the role of unconscious ethnic processing (across ethnic groups) and its link to explicit components is needed. The IAT could provide evidence that even when explicit measures suggest that racial or other biases do not exist, consumers may hold strong stereotypes, and these situations might need special attention, educational efforts, or other interventions.

Aside from race, one could use of the IAT to better understand implicit attitudes toward risky behaviors (e.g., smoking, drinking, condom use) because political correctness and social desirability might tend to influence explicit answers on these issues. Similarly, the IAT can be useful to study reactions to companies' social responsibility programs, and help better predict when and how "doing good will also do well" for the company (Sen \& Bhattacharya, 2001). 
Results from Study 1 demonstrate the IAT's usefulness for measuring the degree to which brands are a part of a consumer's self-concept. These findings demonstrate the IAT's potential for advancing research concerning brand relationships (Fournier, 1998), brand community (McAlexander, Schouten, \& Koenig, 2002; Muniz \& O'Guinn, 2001), and consumer identity. The IAT is also applicable to research on organizational identification (Bergami \& Bagozzi, 2000) and would allow for new understanding and measures of the overlap between self-definition and organizational identity and new insights on its likely impact on other marketing variables.

The IAT may provide unique and important information on other topics in brand management as well. Consumers' associative brand networks may include concepts and associations that a consumer either cannot or will not report, but which may surface through the IAT. Further, because a successful brand extension or brand alliance would share at least some of the traits associated with the core brand (Simonin \& Ruth, 1998), the IAT may expand our understanding of this transfer process.

Ultimately, we would like to suggest that the IAT be used not just as a dependent measure, but also as an independent one or in conjunction with others. Much insight could come from using the IAT as an explanatory factor for behavior, choice, or judgments. Although traditional explicit measures often help to understand the link between attitude and behavior, the IAT might nevertheless increase the predictability of behavior by adding an unconscious or implicit component (cf. Maison et al., 2004). In general, any context in which associations between attributes and concepts operate at an implicit level would provide a suitable and necessary setting for the use of the IAT.

In conclusion, the IAT appears to be both a valuable and valid measure of implicit consumer social cognitions. Of course, we have already acknowledged that the measure is not a complete panacea and that some limitations or concerns still remain. In particular, the relative nature of the measure makes it impractical in some consumer settings. Also, more is needed to be known with respect to the theoretical and physiological underpinnings of how the IAT operates. Finally, more evidence is needed to fully evaluate the IAT's relationship to behavior and the conditions associated with it. However, it appears that the benefits and potential gains for consumer research outweigh these concerns and the IAT provides a much-needed implicit measure with strong psychometric properties.

\section{ACKNOWLEDGMENTS}

We acknowledge the research assistance of Cathleen Collins and her collaboration in the preparation of earlier versions of this manuscript. We thank the editor and the reviewers for their feedback and guidance in the review process. Part of this research was funded by research grants from the Boston University School of Management Faculty Development fund.

\section{REFERENCES}

Anderson, J. R., \& Bower, G. H. (1973). Human associative memory. Washington, DC: Winston.

Asendorpf, J. B., Banse R., \& Mücke, D. (2002). Double dissociation between implicit and explicit personality concepts; the case of shy behavior. Journal of Personality and Social Psychology, 83, 380-393.

Banaji, M. R. (2001). Implicit attitudes can be measured. In H. L. Roediger, III, J. S. Nairne, I. Neath, \& A. Surprenant (Eds.), The nature of remembering: Essays in honor of Robert G. Crowder (pp. 117-150). Washington, DC: American Psychological Association.

Banaji, M. R., \& Hardin, C. D. (1996). Automatic stereotyping. Psychological Science, 7, 136-141.

Banse, R., Seise, J., \& Zerbes, N. (2001). Implicit attitude toward s homosexuality: Reliability, validity, and controlability of the IAT. Zeitschrift für Experimentelle Psychologie, 48, 145-160.

Bargh, J. A. (1989). Conditional automaticity: Varieties of automatic influence in social perception and cognition. In J. S. Uleman \& J. S. Bargh (Eds.), Unintended thought (pp. 3-51). New York: Guilford.

Bargh, J. A. (1994). The four horsemen of automaticity: Awareness, intention, efficiency and control in social cognition. In R. S. Wyer, Jr., \& T. K. Srull (Eds.), Handbook of social cognition (2nd ed., pp. 1-40). Hillside, NJ: Lawrence Erlbaum Associates, Inc.

Bargh, J. A. (2002). Losing consciousness: Automatic influences on consumer judgment, behavior, and motivation. Journal of Consumer Research, 29, 280-285.

Bargh, J. A., Chaiken, S., Govender, R., \& Pratto, F. (1992). The generality of the automatic attitude activation effect. Journal of Personality and Social Psychology, 62, 893-912.

Battig, W. F., \& Montague, W. E. (1969). Category norms for verbal items in 56 categories: A replication and extension of the Connecticut category norms. Journal of Experimental Psychology Monographs, 80(3, Pt. 2).

Belk, R. W. (1988). Possessions and the extended self. Journal of Consumer Research, 15, 139-168.

Bellezza, F. S., Greenwald, A. G., \& Banaji, M. R. (1986). Words high and low in pleasantness as rated by male and female college students. Behavior Research Methods, Instruments, \& Computers, 18, 299-303.

Bergami, M., \& Bagozzi, R. P. (2000). Self-Categorization, affective commitment and group self-esteem as distinct aspects of social identity in the organization. British Journal of Social Psychology, 39, 555-577.

Brendl, C. M., Markman, A. B., \& Messner, C. (2001). How do indirect measures of evaluation work? Evaluating the inference of prejudice in the Implicit Association Test. Journal of Personality and Social Psychology, 81, 760-773.

Brown, S. P., \& Stayman, D. M. (1992). Antecedents and consequences of attitude toward the ad: A meta-analysis. Journal of Consumer Research, 19, 34-51.

Campbell, D. T. (1950). The indirect assessment of social attitudes. Psychological Bulletin, 47, 15-38.

Chaiken, S., \& Bargh, J. A. (1993). Occurrence versus moderation of the automatic attitude activation effect: Reply to Fazio. Journal of Personality and Social Psychology, 6, 759-765.

Churchill, G. A. (1995). Marketing research: Methodological foundations (6th ed.). Fort Worth, TX: Dryden.

Collins, A. M., \& Loftus, E. F. (1975). A spreading-activation theory of semantic processing. Psychological Review, 82, 407-428.

Cunningham, W. A., Johnson, M. K., Gatenby, J. C., Gore, J. C., \& Banaji, M. R. (2003). Neural components of social evaluation. Journal of Personality and Social Psychology, 85, 639-649.

Cunningham, W. A., Preacher, K. J., \& Banaji, M. R. (2001). Implicit attitude measures: Consistency, stability, and convergent validity. Psychological Science, 12, 163-170.

Dasgupta, N., \& Greenwald, A. G. (2000). Exposure to admired group members reduces automatic intergroup bias. Journal of Experimental Social Psychology, 36, 316-328. 
Dasgupta, N., \& McGhee, D. E. (2000). Automatic preference for White Americans: Eliminating the familiarity explanation. Journal of Experimental Social Psychology, 36, 316-330.

De Houwer, J. (2001). A structural and process analysis of the Implicit Association Test. Journal of Experimental Social Psychology, 37, 443-451.

Demo, D. (1985). The measurement of self-esteem: Refining our methods. Journal of Personality and Social Psychology, 48, 1490-1502.

Deshpande, R., \& Stayman, D. M. (1994). A tale of two cities: Distinctiveness theory and advertising effectiveness. Journal of Marketing Research, 31, 57-64.

Devine, P. G. (1989). Stereotypes and prejudice: Their automatic and controlled components. Journal of Personality and Social Psychology, 56, $5-18$.

Devine, P. G. (2001). Implicit prejudice and stereotyping: How automatic are they? Introduction to the special section. Journal of Personality and Social Psychology, 81, 757-759.

Dovidio, J. F., \& Fazio, R. H. (1992). New technologies for the direct and indirect assessment of attitudes. In J. M. Tanur (Ed.), Questions about questions: Inquiries into the cognitive bases of surveys (pp. 204-237). New York: Sage.

Fazio, R. H. (1986). How do attitudes guide behavior? In R. M. Sorrentino \& E. T. Higgins (Eds.), Handbook of motivation and cognition (pp. 204-243). New York: Guilford.

Fazio, R. H. (1995). Attitudes as object-evaluation associations: Determinants, consequences, and correlates of attitude accessibility. In R. E. Petty \& J. A. Krosnick (Eds.), Attitude strength: Antecedents and consequences (pp. 247-282). Hillsdale, NJ: Lawrence Erlbaum Associates, Inc.

Fazio, R. H. (2001). On the automatic activation of associated evaluations: An overview. Cognition and Emotion, 15, 115-142.

Fazio, R. H., Chen, J.-M., McDonel, E. C., \& Sherman, S. J. (1982). Attitude accessibility, attitude-behavior consistency, and the strength of the object-evaluation association. Journal of Experimental Social Psychology, 18, 339-357.

Fazio, R. C., Jackson J. R., Dunton, B. C., \& Williams C. J. (1995). Variability in automatic activation as an unobstrusive measure of racial attitudes; a bona fide pipeline? Journal of Personality and Social Psychology, 69, 1013-1027.

Fazio, R. H., \& Olson, M. A. (2003). Implicit measures in social cognition research: Their meaning and use. Annual Review of Psychology, 54, 297-327.

Fazio, R. H., Sanbonmatsu, D. M., Powell, M. C., \& Kardes, F. R. (1986). On the automatic activation of attitudes. Journal of Personality and Social Psychology, 50, 229-238.

Forehand, M. R., \& Deshpande, R. (2001). What we see makes us who we are: Priming ethnic self-awareness and advertising response. Journal of Marketing Research, 38, 336-348.

Forehand, M. R., \& Perkins, A. (2003). Unconscious processing of spokesperson information: The influence of implicit cognition. Manuscript submitted for publication.

Fournier, S. (1998). Consumers and their brands: Developing relationship theory in consumer research. Journal of Consumer Research, 24, 343-373.

Gaertner, S. L., \& Dovidio, J. F. (1986). The aversive form of racism. In J. F. Dovidio \& S. L. Gaertner (Eds.), Prejudice, discrimination, and racism (pp. 61-89). Orlando, FL: Academic.

Greenwald, A. G. (1992). Unconscious cognition reclaimed. American Psychologist, 47, 766-779.

Greenwald, A. G., \& Banaji, M. R. (1995). Implicit social cognition: Attitudes, self-esteem, and stereotypes. Psychological Review, 102, 4-27.

Greenwald, A. G., Banaji, M. R., Rudman, L. A., Farnham, S. D., Nosek, B. A., \& Mellott, D. S. (2002). A unified theory of implicit attitudes, stereotypes, self-esteem, and self-concept. Psychological Review, 109, 3-25.

Greenwald, A. G., \& Farnham, S. D. (2000). Using the Implicit Association Test to measure self-esteem and self-concept. Journal of Personality and Social Psychology, 79, 1022-1038.
Greenwald, A. G., Klinger, M. R., \& Liu, T. J. (1989). Unconscious processing of dichoptically masked words. Memory and Cognition, 17, 35-47.

Greenwald, A. G., McGhee, D. E., \& Schwartz, J. L. K. (1998). Measuring individual differences in implicit cognition: The Implicit Association Test. Journal of Personality and Social Psychology, 74, 1464-1480.

Greenwald, A. G., \& Nosek, B. A. (2001). Health of the Implicit Association Test at age 3. Zeitschrift fur Experimentelle Psychologie, 48, 85-93.

Grier, S. A., \& Deshpande, R. (2001). Social dimensions of consumer distinctiveness: The influence of social status on group identity and advertising persuasion. Journal of Marketing Research, 38, 216-224.

Haire, M. (1950). Projective techniques in marketing research. Journal of Marketing, 14, 649-656.

Haugvedt, C. P., Petty, R. E., \& Cacioppo, J. T. (1992). Need for cognition and advertising: understanding the role of personality variables in consumer behavior. Journal of Consumer Psychology, 1, 239-260.

Hawkins, D. I., \& Coney, K. A. (1981). Uninformed response error in survey research. Journal of Marketing Research, 18, 370-374.

Heath, T. B., McCarthy, M. S., \& Mothersbaugh, D. L. (1994). Spokesperson fame and vividness effects in the context of issue-relevant thinking: The moderating role of competitive setting. Journal of Consumer Research, 20, 520-534.

Jacoby, L. L., Lindsay, D. S., \& Toth, J. P. (1992). Unconscious influences revealed. American Psychologist, 47, 802-809.

Janiszewski, C. (1988). Preconscious processing effects: The independence of attitude formation and conscious thought. Journal of Consumer Research, 15, 199-209.

Janiszewski, C. (1993). Preattentive mere exposure effects. Journal of Consumer Research, 20, 376-392.

Jost, J. T., \& Banaji, M. R.(1994). The role of stereotyping in person-system justification and the production of false consciousness. British Journal of Social Psychology, 33, 1-27.

Kamins, M. A. (1990). An investigation into the 'match-up' hypothesis in celebrity advertising: When beauty may be only skin deep. Journal of Advertising, 19, 4-13.

Karpinski, A., \& Hilton, J. L. (2001). Attitudes and the Implicit Association Test. Journal of Personality and Social Psychology, 81, 774-788.

Kawakami, K., Dion, K. L., \& Dovidio, J. F. (1998). Racial prejudice and stereotype activation. Personality and Social Psychology Bulletin, 24, 407-416.

Kihlstrom, J. F. (2004). Implicit methods in social psychology. In C. Sansone, C. C. Morf, \& A. T. Panter (Eds.), The Sage handbook of methods in social psychology (pp. 195-212). Thousand Oaks, CA: Sage.

Kleine, S. S., Kleine, R. E., III, \& Allen, C. T. (1995). How is a possession 'me' or 'not me'? Characterizing types and an antecedent of material possession attachment. Journal of Consumer Research, 22, 327-343.

Kuehnen, U., Schiessl, M., Bauer, N., Paulig, N., Poehlmann, C., \& Schmidthals, K. (2001). How robust is the IAT? Measuring and manipulating implicit attitudes of East and West Germans. Zeitschrift fur Experimentelle Psychologie, 48, 135-144.

Lemon, N. (1973). Attitudes and their measurement. New York: Wiley.

Lilienfeld, S. O., Wood, J. M., \& Garb, N. H. (2001). The scientific status of projective techniques. Psychological Science in the Public Interest, 1, 27-66.

Louie, T., Kulik, R., \& Jacobson, R. (2001). When bad things happen to endorsers of good products. Marketing Letters, 12, 13-23.

MacKenzie, S. B., \& Lutz, R. J. (1996). An empirical examination of the structural antecedents of attitude toward the ad in advertising pretesting context. Journal of Marketing, 53, 48-65.

MacKenzie, S. B., Lutz, R. J., \& Belch, G. E. (1986). The role of attitude toward the ad as a mediator of advertising effectiveness: A test of competing explanations. Journal of Marketing Research, 23, 130-143.

Maison, D., Greenwald, A. G., \& Bruin, R. (2001). The Implicit Association Test as a measure of implicit consumer attitudes. Polish Psychological Bulletin, 32, 1-9.

Maison, D., Greenwald, A. G., \& Bruin, R. (2004). Predictive validity of the Implicit Association Test in studies of brands, consumer attitudes, and behavior. Journal of Consumer Psychology, 14, 405-415. 
McAlexander, J. H., Schouten, J. W., \& Koenig, H. F. (2002). Building brand community. Journal of Marketing, 66, 38-54.

McFarland, S. G., \& Crouch, Z. (2002). A cognitive skill confound on the Implicit Association Test. Social Cognition, 20, 483-510.

Mellott, D. S., \& Greenwald, A. G. (2000, May). Measuring implicit ageism: Do the Implicit Association Test and Semantic Priming measure the same construct? Paper presented at the meeting of the Midwestern Psychological Association, Chicago.

Mick, D. G. (1996). Are studies of dark side variables confounded by socially desirable responding? The case of materialism. Journal of Consumer Research, 23, 106-119.

Mischel, W. (1968). Personality and assessment. New York: Wiley.

Mitchell, A. A. (1986). The effect of verbal and visual components of advertisements on brand attitudes and attitude toward the advertisement. Journal of Consumer Research, 13, 12-24.

Mitchell, A. A., \& Olson, J. C. (1981). Are product attribute beliefs the only mediator of advertising effects on brand attitude? Journal of Marketing Research, 18, 318-332.

Mowen, J. C., \& Spears, N. (1999). Understanding compulsive buying among college students: A hierarchical approach. Journal of Consumer Psychology, 8, 407-430.

Muniz, A. M. J., \& O’Guinn, T. C. (2001). Brand community. Journal of Consumer Research, 27, 412-432.

Netemeyer, R. G., \& Bearden, W. O. (Eds.). (1998). Handbook of marketing scales (2nd ed.). Thousand Oaks, CA: Sage.

Netemeyer, R. G., Burton, S., \& Lichtenstein, D. R. (1995). Trait aspects of vanity: Measurement and relevance to consumer behavior. Journal of Consumer Research, 21, 612-626.

Nosek, B. A., \& Banaji, M. R. (2001). The go/no-go association task. Social Cognition, 19, 625-666.

Nosek, B. A., \& Banaji, M. R. (2002). (At least) two factors mediate the relationship between implicit and explicit attitudes. In R. K. Ohme \& M. Jarymowicz (Eds.), Natura automatyzmow (pp. 49-56). Warszawa, Poland: WIP PAN \& SWPS.

Nosek, B. A., Banaji, M. R., \& Greenwald, A. G. (2002a). Harvesting implicit group attitudes and beliefs from a demonstration website. Group Dynamics, 6, 101-115.

Nosek, B. A., Banaji, M. R., \& Greenwald, A. G. (2002b). Math = male, me $=$ female, therefore math doesn't equal me. Journal of Personality and Social Psychology, 83, 44-59.

Peter, J. P. (1979). Reliability: A review of psychometric basics and recent marketing practices. Journal of Marketing Research, 16, 6-17.

Phelps, E. A., O'Connor, K. J., Cunningham, W. A., Funayama, E. S., Gatenby, J. C., Gore, J. C., et al. (2000). Amygala activation predicts performance on indirect measures of racial bias. Journal of Cognitive Neuroscience, 12, 729-738.

Rapaport, D., Gill, M. M., \& Schafer, R. (1968). Diagnostic psychological testing (Rev. ed.). New York: International University Press.

Rothermund, K., \& Wentura, D. (2001). Figure-ground asymmetries in the Implicit Association Test. Zeitschrift fur Experimentelle Psychologie, 48, 94-106.

Rozin, P., \& Singh, L. (1999). The moralization of cigarette smoking in the United States. Journal of Consumer Psychology, 8, 339-342.

Rudman, L. A., Feinberg, J., \& Fairchild, K. (2002). Minority members' implicit attitudes: Automatic ingroup bias as function of group status. Social Cognition, 20, 294-320.

Rudman, L. A., \& Glick, P. (2001). Prescriptive gender stereotypes and backlash against agentic women. Journal of Social Issues, 57(4), 743-762.
Rudman, L. A., \& Kilianski, S. E. (2000). Implicit and explicit attitudes towards female authority. Personality and Social Psychology Bulletin, 26, $1315-1328$.

Schmitt, B. H. (1994). Contextual priming of visual information in advertisements. Psychology and Marketing, 11, 1-14.

Schwarz, N., \& Bohner, G. (2001). The construction of attitudes. In A. Tesser \& N. Schwarz (Eds.), Blackwell handbook of social psychology: Intraindividual processes (pp. 413-435). Oxford, England: Blackwell.

Sen, S., \& Bhattacharya, C. B. (2001). Does doing good always lead to doing better? Consumer reactions to corporate social responsibility. Journal of Marketing Research, 38, 225-243.

Shapiro, S. (1999). When an ad's influence is beyond our conscious control: Perceptual and conceptual fluency effects caused by incidental ad exposure. Journal of Consumer Research, 26, 16-36.

Shrum, L. J., Wyer, R. S. Jr., \& O'Guinn T. C. (1998). The effects of television consumption on social perspectives: The use of priming procedures to investigate psychological processes. Journal of Consumer Research, $24,447-458$.

Simonin, B. L., \& Ruth, J. A. (1998). Is a company known by the company it keeps? Accessing the spillover effects of brand alliances on consumer brand attitudes. Journal of Marketing Research, 35, 30-42.

Sirgy, M. J. (1982). Self-concept in consumer behavior: A critical review. Journal of Consumer Research, 9, 287-300.

Snyder, M., Omoto, A. M., \& Crain, A. L. (1999). Punished for their good deeds: Stigmatization of AIDS volunteers. American Behavioral Scientist, 42(7), 1175-1192.

Steffens, M. C., \& Plewe, I. (2001). Items' cross-category associations as a confounding factor in the Implicit Association Test. Zeitschrift fur Experimentelle Psychologie, 48, 123-134.

Tulving, E., \& Schacter, D. L. (1990). Priming and human memory systems. Science, 247, 301-306.

Weinberger, J. (2000). William James and the unconscious: Redressing a century-old misunderstanding. Psychological Science, 11, 439-445.

Wyer, R. S., \& Srull, T. K. (1989). Memory and cognition in its social context. Hillsdale, NJ: Lawrence Erlbaum Associates, Inc.

Wong, N. C. (2001, December 4). Apple's time to grow; computer maker expanding in downturn. The Washington Post, p. E01.

Yi, Y. (1993). Contextual priming effects in print advertisements: The moderating role of prior knowledge. Journal of Advertising, 22, 1-12.

Zaltman, G. (2000). Consumer researchers: Take a hike! Journal of Consumer Research, 26, 423-428.

Received: September 11, 2003

Accepted: November 2, 2003

\section{APPENDIX \\ Examples of Advertising Stimuli Used for Study 2}

Note that all ads were executed for both brands. This appendix contains examples of the stimuli used in Study 2. In total there were 32 versions created ( 2 brands $\times 8$ sports $\times 2$ ethnicities). Actual faces have been masked in this appendix, but they were not masked in the experiment. 

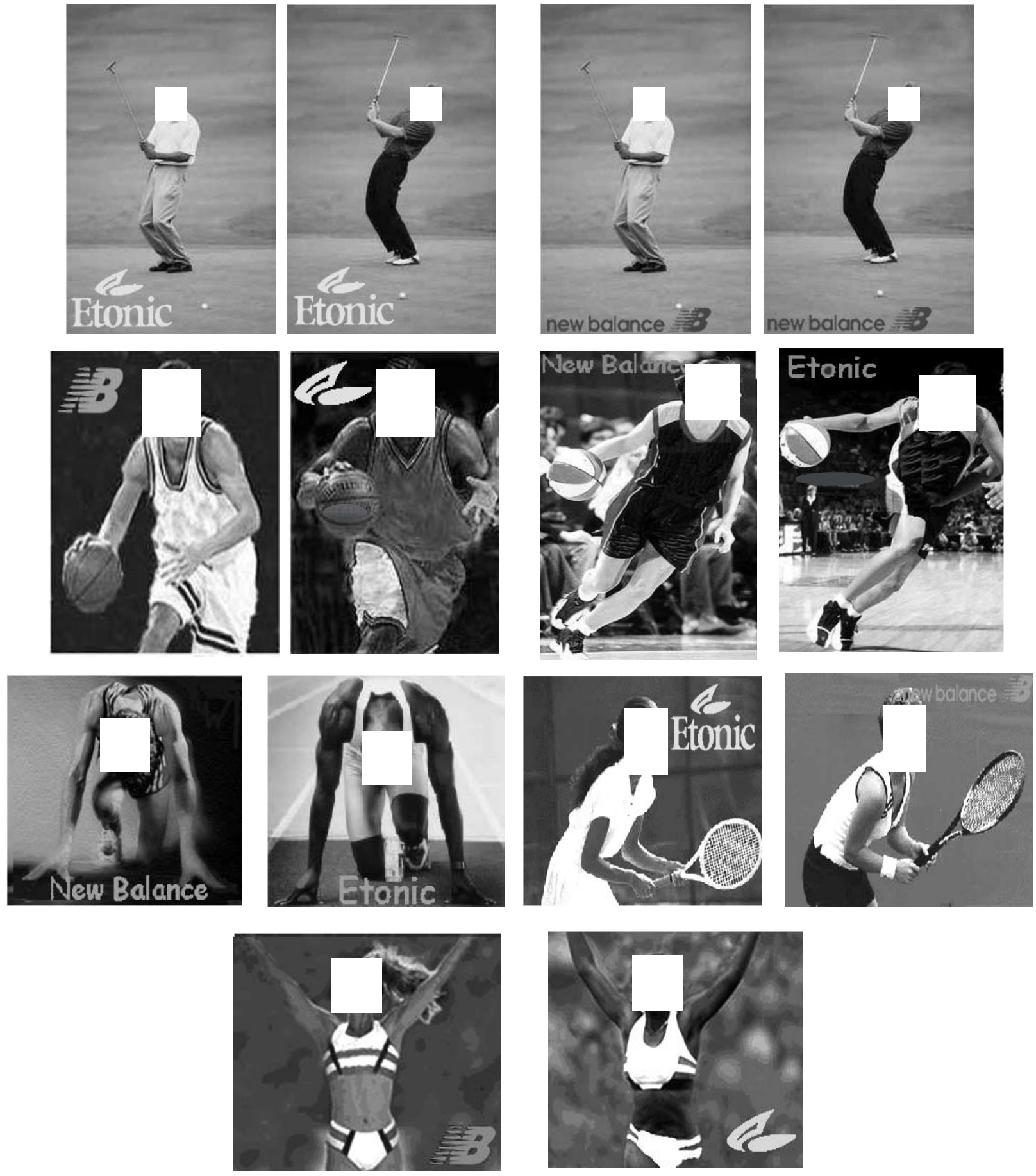